\title{
Engineering Investigations and Durability Problems of the Construction Materials of the Roman Babylon of Egypt
}

\author{
Sayed Hemeda1, Adel I. M. Akarish², Amr Abu El-Nagga1 \\ ${ }^{1}$ Conservation Department, Faculty of Archaeology, Cairo University, Cairo, Egypt \\ ${ }^{2}$ Geological Sciences Department, National Research Centre, Cairo, Egypt \\ Email: sayed.hemeda@cu.edu.eg,akarish1@hotmail.com,Amr_aboalnaga93@yahoo.com
}

How to cite this paper: Hemeda, S., Akarish, A.I.M. and El-Nagga, A.A. (2018) Engineering Investigations and Durability Problems of the Construction Materials of the Roman Babylon of Egypt. Open Journal of Geology, 8, 404-436.

https://doi.org/10.4236/ojg.2018.84024

Received: March 8, 2018

Accepted: April 20, 2018

Published: April 23, 2018

Copyright (c) 2018 by authors and Scientific Research Publishing Inc. This work is licensed under the Creative Commons Attribution International License (CC BY 4.0).

http://creativecommons.org/licenses/by/4.0/

\section{Abstract}

The Babylon of Egypt was constructed in the Roman period (300 AD), in the old Cairo area. It is one of the most distinguished monuments in the universal architectural heritage. The present study introduces the characteristics of roman and byzantine bricks and their joining structural mortars used in the roman fortress in order to risk assessment and to define the necessary characteristics of the intervention retrofitting new materials, which will be used in the ongoing preservation work of this fortress. To achieve such, several analyses and laboratory tests like ultra-sonic pulse method testing (ultrasonic pulse velocity, dynamic modulus of elasticity), uniaxial compression test and Brazilian splitting tension test, were carried out to determine their basic, mechanical and engineering properties, along with the microstructural properties determination using Mercury porosimeter. On the other hand, the morphological description, petrography, mineralogical and microstructural properties were determined using scanning electron microscope equipped by EDS, polarizing light microscopy, XRD and XRF. The obtained results indicated that the joining structural mortars are ranging from medium to stiff, low compacted, having hydraulic properties due to the use of natural furnace slag, brick powder, brick fragments and aggregates that match with the pozzolanic properties and also rich in active silica and alumina. The examinations reveal the use of limestone fractions as coarse aggregates or fillers. On the other hand, the Roman bricks consist mainly on quartz and feldspars embedded in a matrix of iron oxide and burnt clays. Also the obtained results indicated that old bricks were of low apparent specific density (1.4 - 1.7), medium absorption $(10 \%-20 \%)$ and low uniaxial compressive strength $(2-10 \mathrm{MPa})$, with Young's modulus 1.2 to $3 \mathrm{GPa}$. The ultra-sonic wave velocity is 1.7 to $2 \mathrm{~km} / \mathrm{s}$, with dynamic modulus of elasticity 2.4 to $4 \mathrm{MPa}$. The shear modulus is 917 to 
$1500 \mathrm{MPa}$. These results may be due to large pores and cracks into their matrix. Due to their surface roughness, the adhesion with the lime mortars was relatively high.

\section{Keywords}

Babylon of Egypt, Characterization, Durability, Engineering Property, Hydraulic Lime Mortar, Roman Brick

\section{Introduction}

The field observations and site investigations of the construction materials and structural elements remains of the Babylon of Egypt revealed a sequence of continuous occupation extending from the sixth century BC to the present day, Figure 1. These include the massive stone/brick walls of the canal linking the Nile to the Red Sea, and the harbor constructed by Trajan at its entrance around AD 110. Diocletian built the fortress of Babylon around the harbor and the canal in $\mathrm{AD} 300$, and much new information has come to light concerning the construction and internal layout of the fortress, which continues to enclose and define the enclave of Old Cairo with its famous churches like the Hanging church, Abu Serga church and Saint George church, Figure 2(a) and Figure 2(b).

Preservation of historic buildings and archaeological sites in particularly with old fired brick masonry structures requires a thorough understanding of the mineral composition, behavior, physiochemical and mechanical properties of these construction materials, as well as their microstructures, the role of the microstructure in controlling the engineering properties and performance of these construction materials, and the properties that were particularly responsible for long-term durability and performance [1].

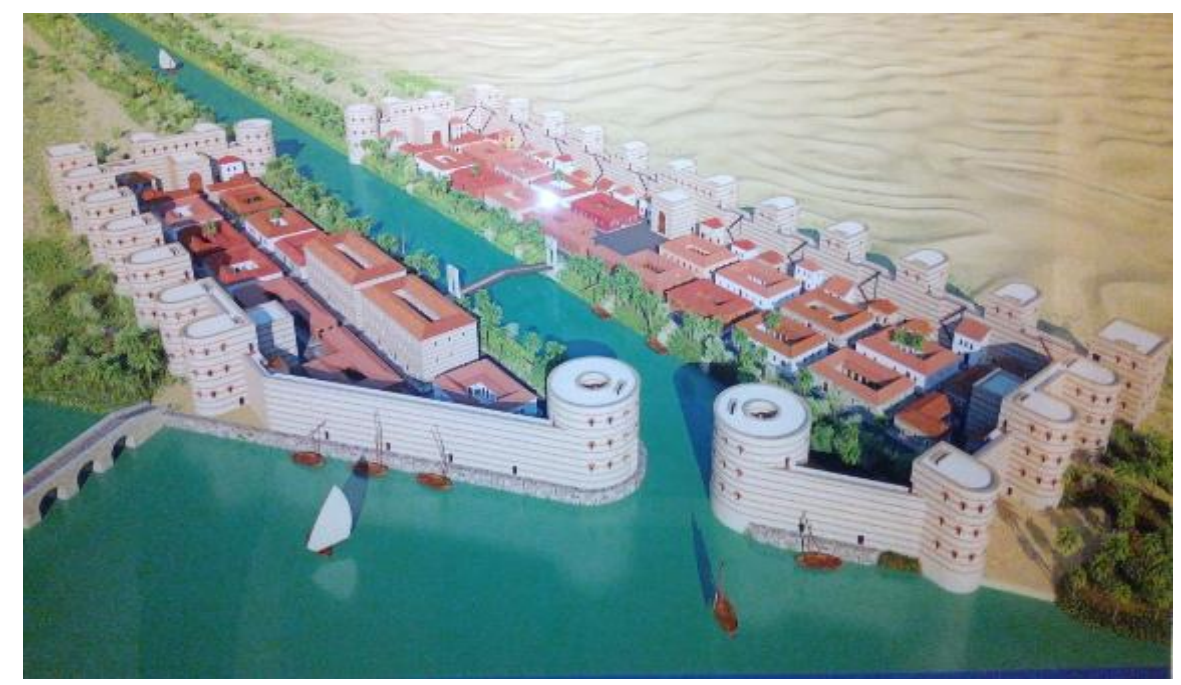

Figure 1. General layout of the fortress of Babylon of Egypt on the first century AD. (Sheehan, 2015). 


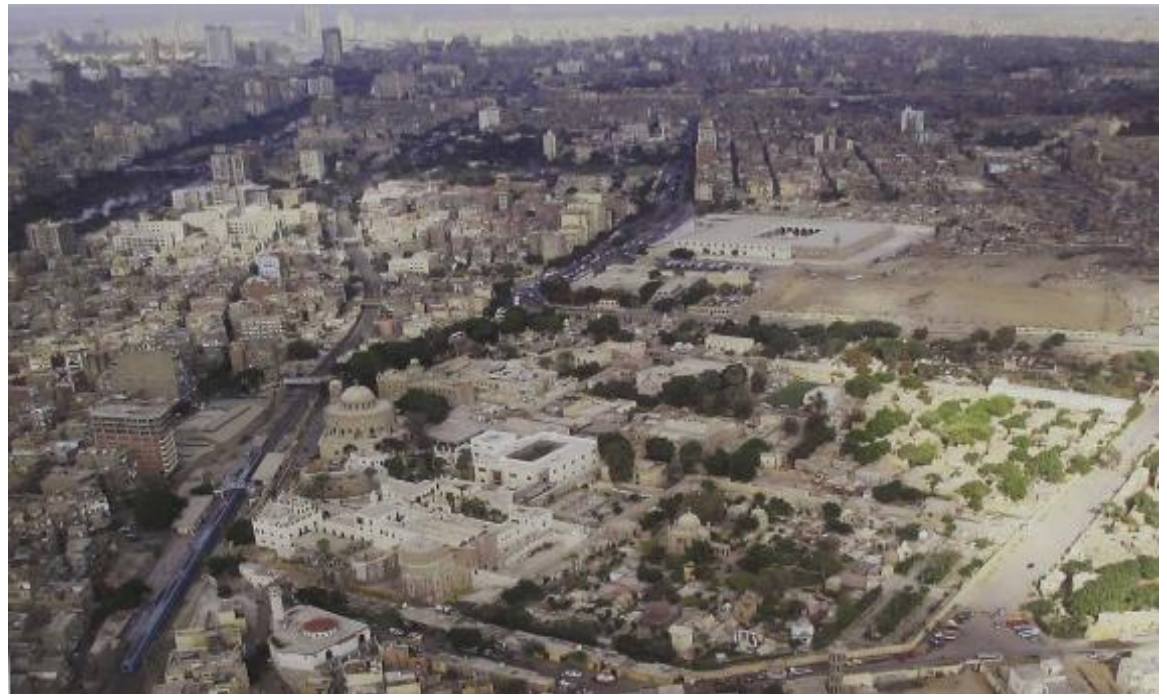

(a)

1 - the Hanging church

2 - coptic museum

3 - Geore's church

4 - Abu ssrja church

5 - Jewish temple

6 - church of saint barbara

7 - The tomb of ibrahim el-gohary

8 - St. george monastery
9 - Wedding hall of st. george

10 - Hanging church towers

11 - South tower round

12 - Greek tower

13 - The south tower east

\section{4- Applicatin wall} The remaining archaeologist inside the fortress of Babylon

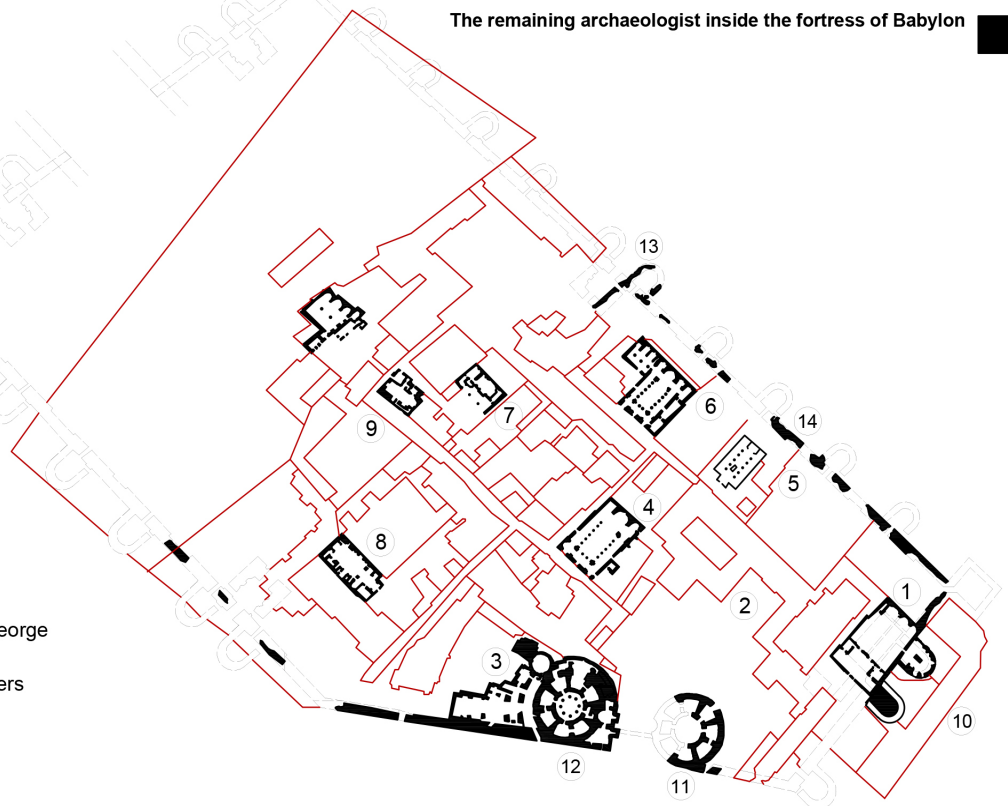

General planning for the fortress of Babylon in region of ancient egypt

(b)

Figure 2. (a) Recent aerial view showing the general layout of Babylon of Egypt. (b) General planning for the fortress of Babylon of ancient Egypt.

Fired brick masonry constitutes a significant part of the construction materials found in the byzantine and roman historic buildings and archaeological sites. The results of the fired brick units investigations could be used to evaluate the suitability of the bricks as replacements for original masonry materials and 
to predict their performance once in place. Old fired bricks are difficult to characterize due to the wide diversity of local raw materials, manufacturing processes, and conservation states. The engineering and mineralogical properties of historical fired brick exhibit a large spectrum and a wide variability.

During the Roman period, fired bricks started dominating in constructions either sole ("opus testaceum") or in combination with stones ("opus mixtum") like the Babylon of Egypt, our present case study. With the systematic use of fired bricks, the width of joints increased, leading to the decrease of the constructions' weight and to the increase of their height [2]. In Byzantium, brick masonries prevailed, offering a variety of structural elements built with fired bricks (domes, arches, and pillars) [3].

Some researchers investigated the effects of pozzolanic materials such as ground granulated blast furnace slag, brick or tiles powder and fly ash on lime based or air dried lime mortars composed of these admixtures and the lime [1]-[8]. Some researchers studied the characterization of these modified hydraulic mortars applied to structures of certain Early Byzantine period and Roman time [9] [10] [11] any researchers [12], it was determined that these consisted primarily of strongly carbonated air lime to which pozzolanic aggregates had been added. The purpose of another study was to trace a constructive history by means of chemical and mineralogical analysis of the mortars used [13]. The different binders and aggregates used, coming from different quarries, could thus suggest the existence of various moments of construction, with an expansion of the built structures [14]-[19].

The aim and scope of this study is to investigate and analyze the construction and building materials used in the Babylon of Egypt, which was built during the Roman time, in order to define their mineralogical characteristics and engineering properties and to consider the properties of original materials, thus enlightening the usability of them in repair of such buildings. For this purpose, a large number of samples of the construction materials like coating and structural mortars and fired bricks were taken and the mineralogical characteristics and engineering properties of these materials were investigated.

\section{The Structural and Architectural Description of the Babylon of Egypt}

According to the current field study, the fortress is surrounded by an irregular wall, which includes inside it several towers belonging to the fort together with a group of ancient archaeological churches. Some of these churches are constructed on the fortress itself, while the others are constructed adjacent to it as the Hanging church and the Greek Mary Girgis church.

Most of the old parts of the fortress were constructed in unified style. Its rows of limestone and brick courses pervaded with some slots and windows in its middle. The towers present in the area of the fortress (or Roman Babylon) are presented in the next sections. 


\subsection{The Hanging Church Towers: It Has Two Roman Towers}

1) The first tower, it is about $13 \mathrm{~m}$ height and its essential component is the wage bricks with some elements of limestone in different parts, either are old especially in the lower part or new. The upper part is covered with white wash layers in some parts with (three) limestone lines belt. It contains five large windows and other small ones. They are topped by group of arches of limestone and wage bricks. Also, four solid entries from irregular wage bricks and limestone group pervaded with irregular wage bricks lines are present. At the upper middle of the tower, there are (there) solid windows of ceramic tile, which are decorated with plant decoration and Geometric motifs. Two iron digitations are present $\{\mathrm{G} 3\}$

2) The second tower: It is lower than the first one (height is about $11 \mathrm{~m}$, Figure 4(a). The essential element is the wage bricks with some regular rows of limestone in different parts. The bottom part was built of old limestone, in which some parts are ruined and are replaced by new limestone in the frame of the contract 102. It has three big and six small holes with arches. Also, has three solid entries having different sizes of ruined limestone courses with regular wage bricks lines, Figure 3 and Figure 4.

\subsection{The Greek Tower}

It has two frontages and was rebuilt within the Contract 102; groundwater control system has been constructed to lower the water table below the floor levels. The first frontage is nine sections each one is formed of five rows of limestone and eight rows of limestone and three rows of wage bricks. -The height of this frontage is $10.14 \mathrm{~m}$ from the ground level. The second frontage is located by the fort's entrance beside the Coptic museum and has nine sections, each one is five lines of limestone, also eight sections of wage bricks, and each section is from

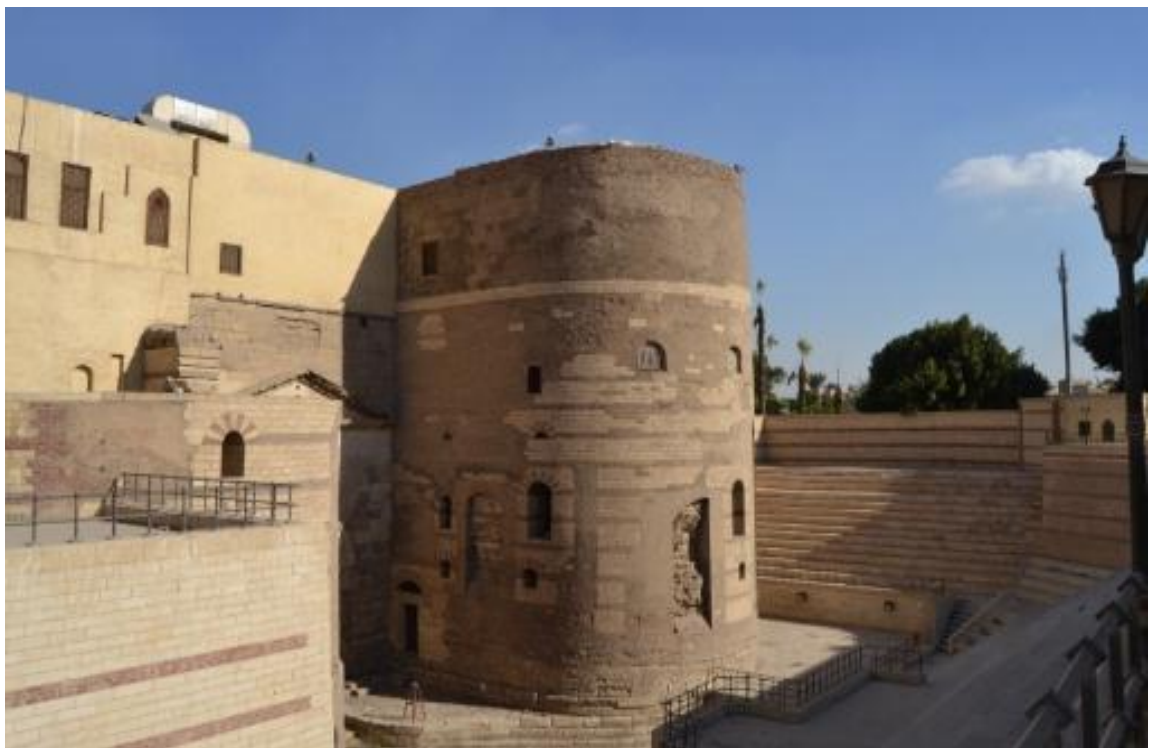

Figure 3. A roman towers underneath of the hanging church. 


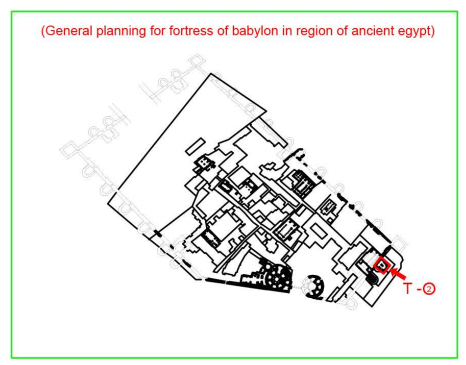

\section{Hanging church towers}
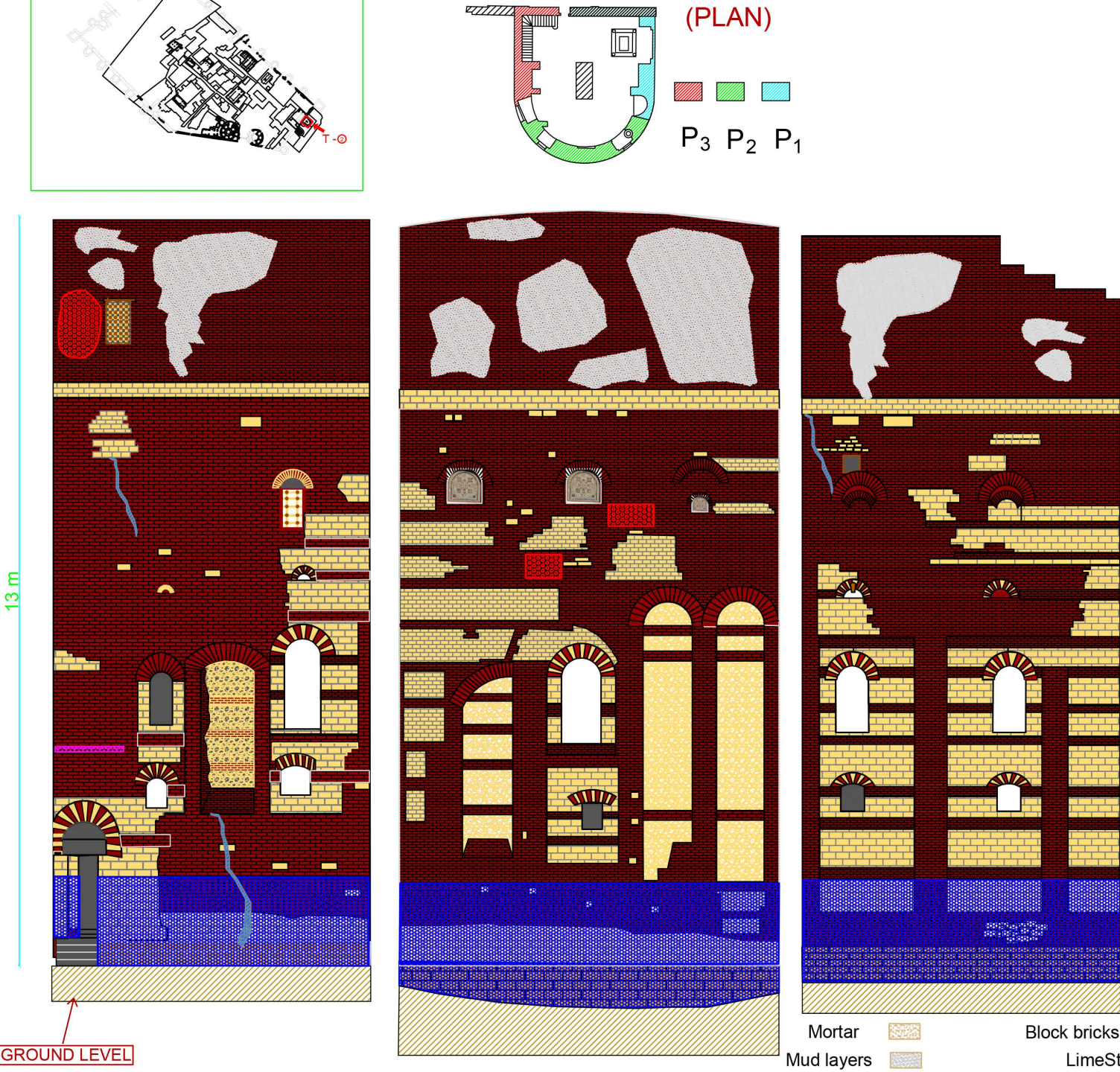

$\mathrm{P}_{3}$

Cracks and breaks

Ground water and salts

Hanging church towers $\mathrm{T}-2$
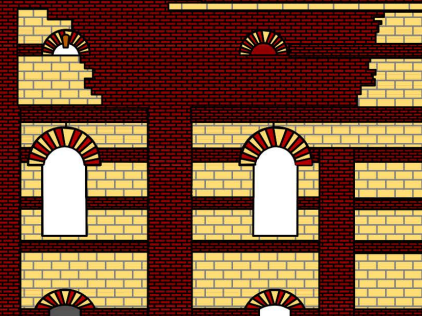

1

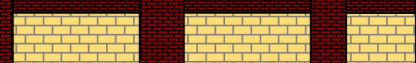

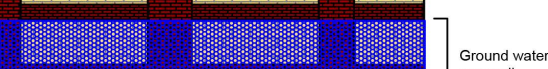

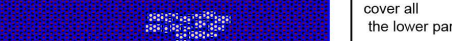
6. the lower part

\section{(ELEV)}

Figure 4. Architectural documentation and degradation map of the roman towers underneath of the hanging Church.

three lines. It has a large round arch in its middle, which is closed by a large iron wall and on the left and right there are small windows with an iron wall that closes it. This frontage high is $9.73 \mathrm{~m}$ from the ground level, Figure 5(a).

\subsection{The Southern Round Tower}

The southern round tower, it is located by the entrance of the fort and was 


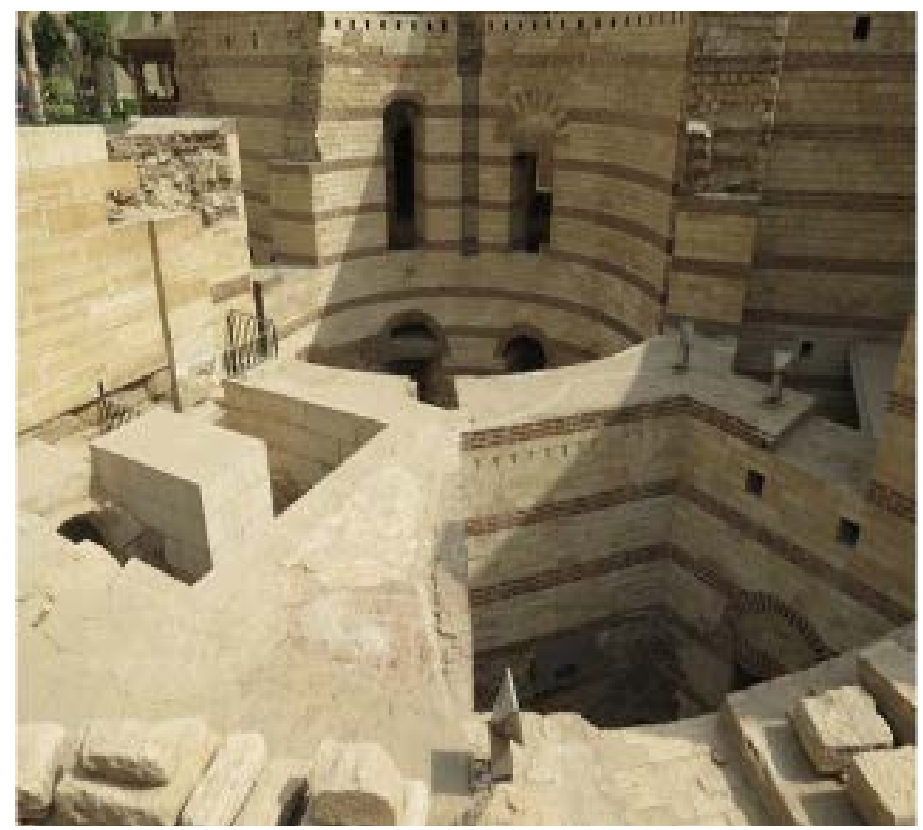

(a)

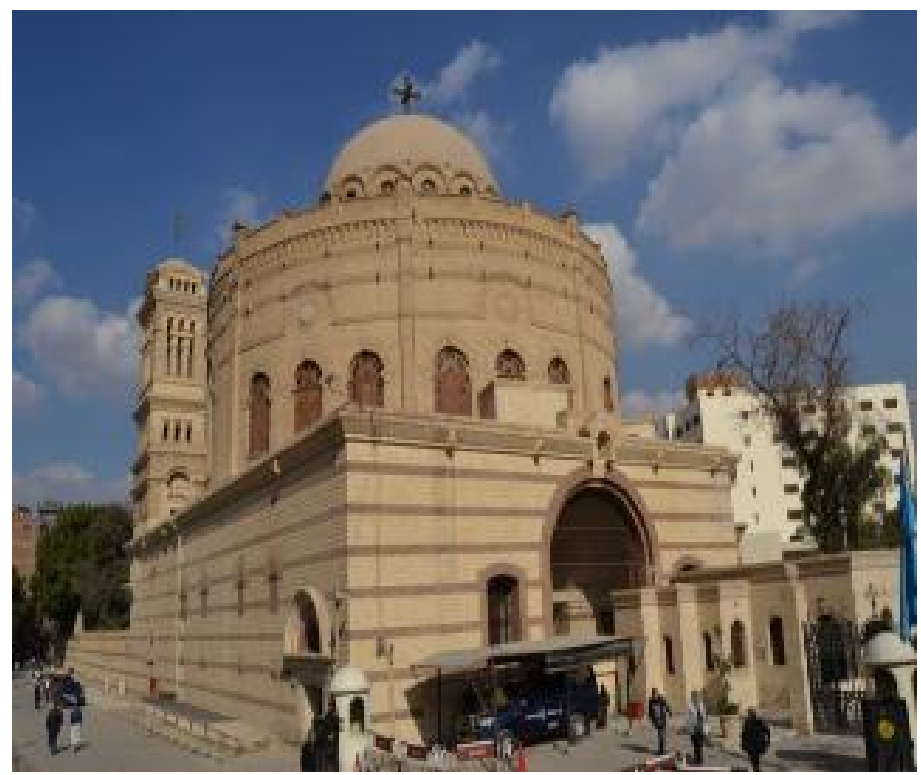

(b)

Figure 5. (a) round south tower of the Babylon of Egypt (b) Saint George Church built on the roman tower (Greek tower).

constructed in the same manner of the fort's tower. It has five-sections of limestone; everyone is (seven) rows of limestone. The sections formed of wage bricks are (seven) section of (three) rows attached with lime mortar, which was used in a common way in the Roman age. This tower has grouped of windows with a round arch above them in equal distances rotate the whole tower, Figure 5(b). Figure 6 presents the degradation map of the walls of the south round tower next to the Coptic Museum (a) and level of the roman tower underneath of the Greek Church (b). 


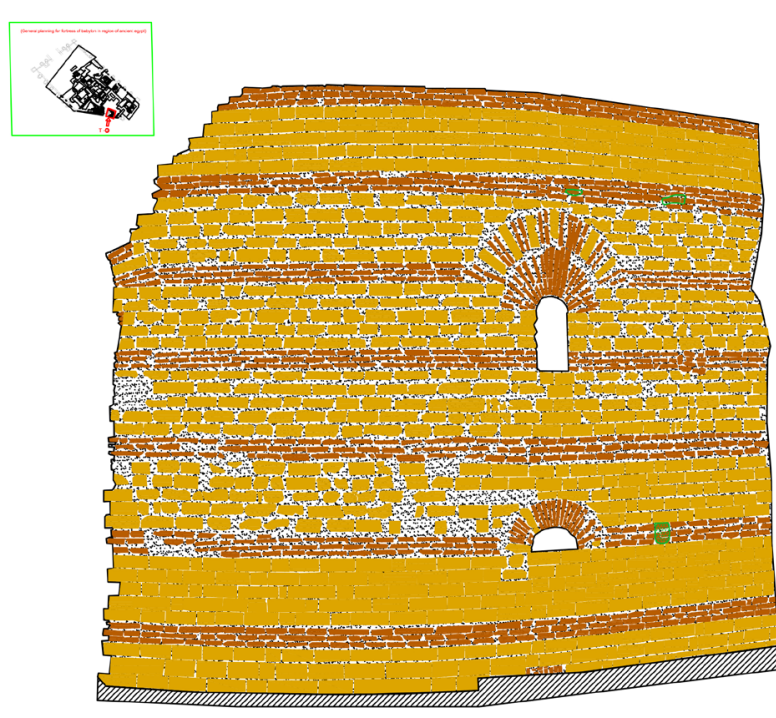

South tower round - the western facade $T$-(4)

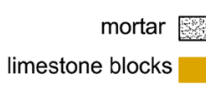

ground level
Block brick wage

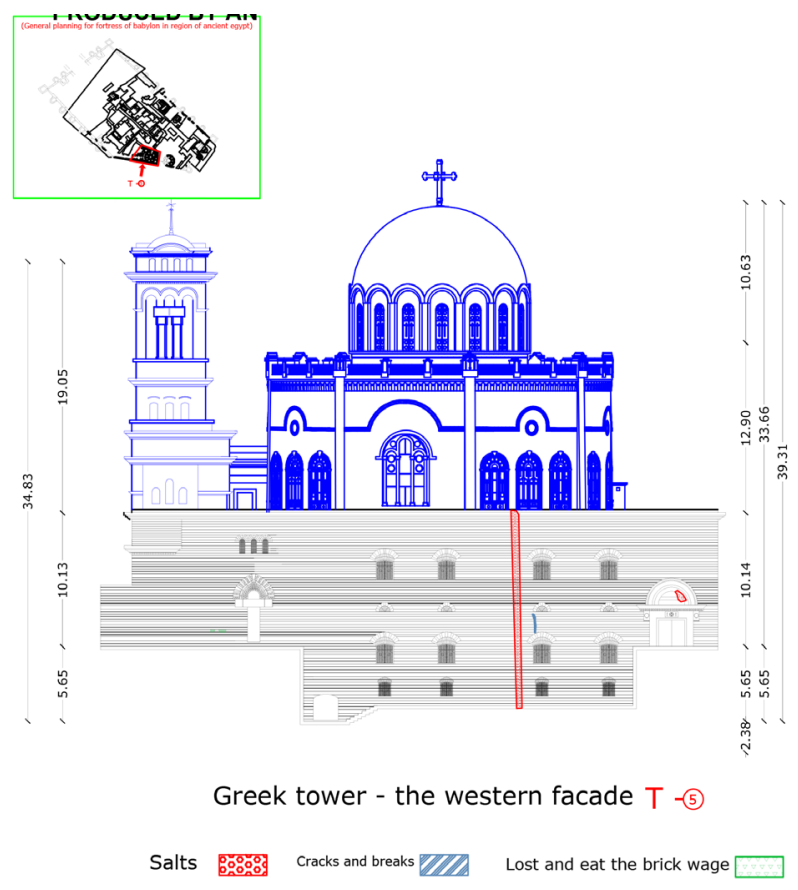

Figure 6. Degradation maps of the wall of the south round tower next to the Coptic Museum (a) and level of the roman tower underneath of the Greek Church (b).

\subsection{The South East Tower}

It is located next to the tombs and separated into two parts, vertical and rounded parts. 1) The vertical part contains two divisions. The first division, which though to be new, is formed of five sections of limestone, each one is (five) rows, in addition to (five) lines of wage bricks, each one consists of (3) lines, while, the second division contains two levels. The lower level has $9.95 \mathrm{~m}$ width and its right side rises $8.14 \mathrm{~m}$, where the left is $5.74 \mathrm{~m}$. It is formed of irregular ruined limestone and wage brick. The upper level formed of twelve rows of limestone and twelve rows of wage brick. All are joined by lime mortar which is a common way in that period. A group of irregular ruined limestone found at the top of this level is covered by soot that might be resulted due to burning rubbish next to it. 2) The round part is of about $1.10 \mathrm{~m}$ high and its bottom consists of ruined wage bricks and limestone joined by lime mortar pervaded with good limestone. The upper part is about $5.70 \mathrm{~m}$ height and its width is about $12.40 \mathrm{~m}$, Figure 8 and Figure 9. It formed of fourteen rows of limestone and fourteen rows of wage brick; some of it consists of two, three or five courses lines with mortar to attach them. There's a big break in the upper part and seven missed parts (Figure 7 and Figure 8).

\subsection{The North East Wall}

It is the ancient fort's wall and is located next to the Jewish temple, It has two parts one is old having height about $3.85 \mathrm{~m}$ and width about $12.6 \mathrm{~mm}$, and the other is new with height $2.90 \mathrm{~m}$ and width about $12.06 \mathrm{~m}$. The ancient (old) part 


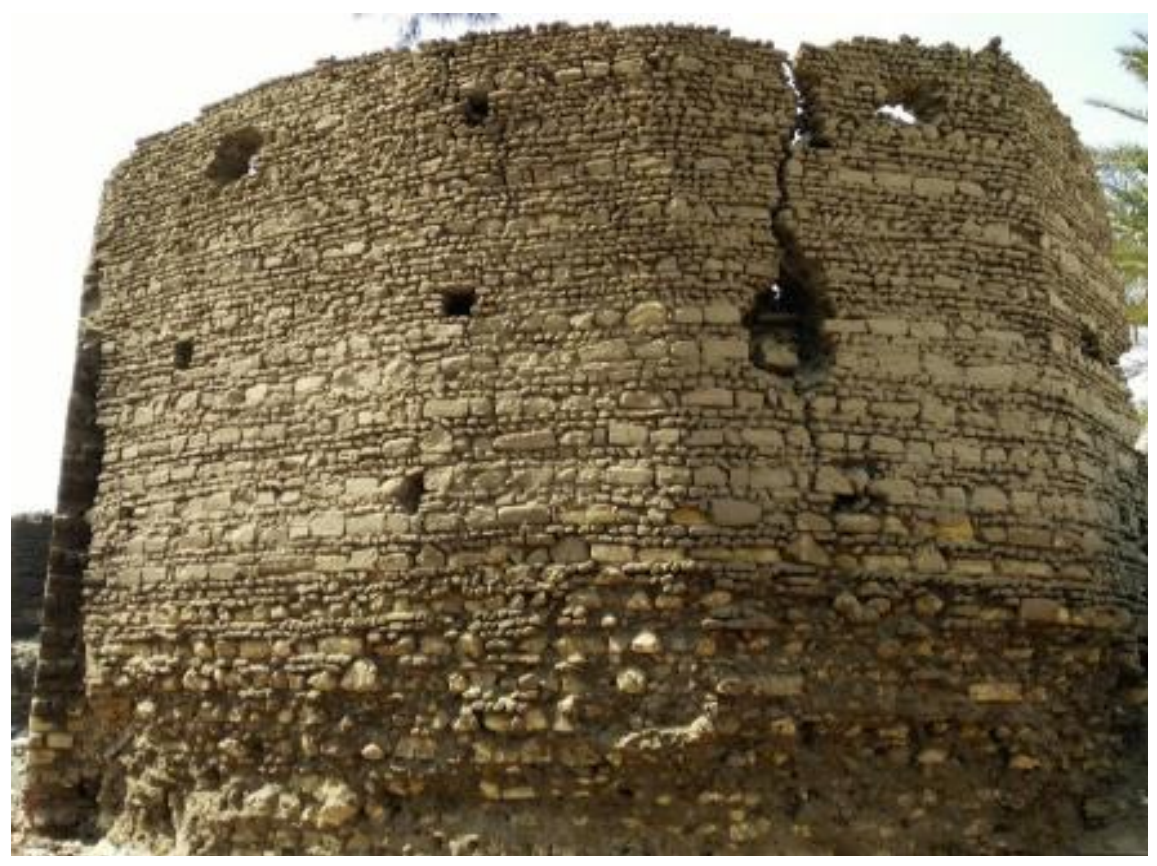

Figure 7. South east tower of the Babylon of Egypt.

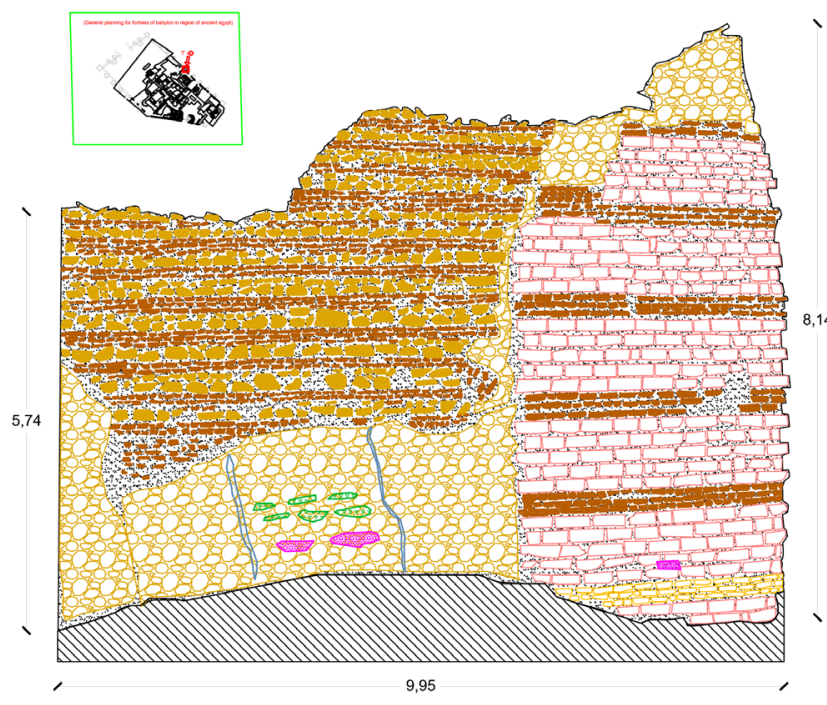

South tower east- the south western facade $T$-(6)
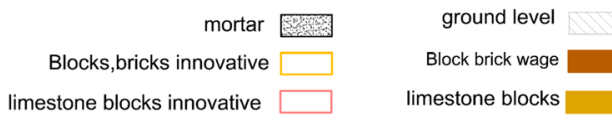

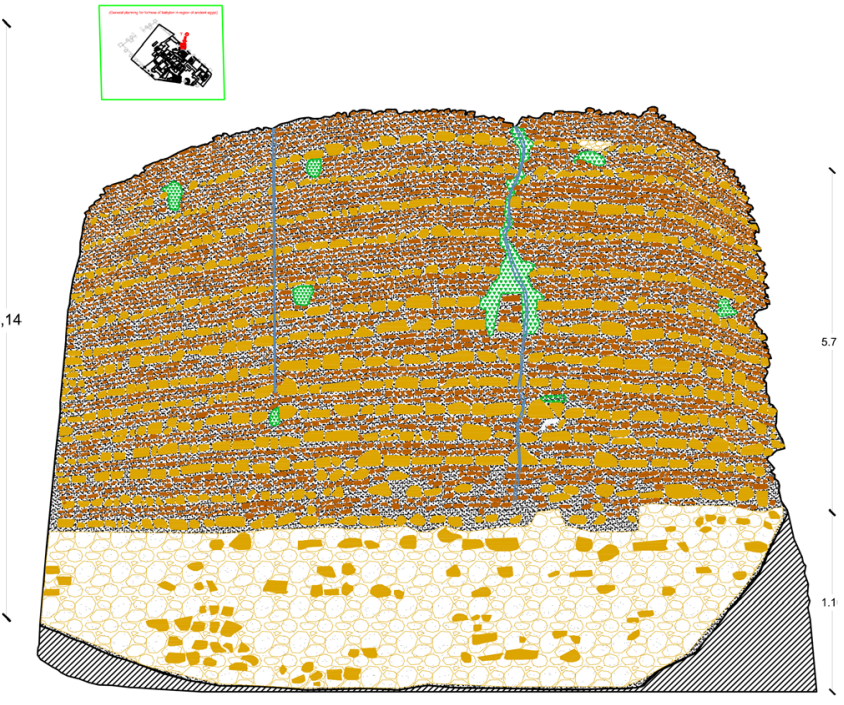

South tower east- the south eastern facade $T$-(6)

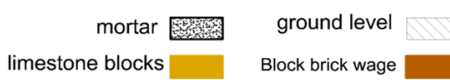

Figure 8. Present state of deterioration of the south east tower next to the Armenian tombs.

of the wall consists of four sections of limestone; every section included five lines and five sections of wage bricks; every section consists of (3) lines. Worth mentioning that, the base of the old part is immersed underneath the soil. It has two solid entries of limestone and wage bricks with a round arch of vertical lines of wage bricks. The limestone entries have dimensions of 2.10, 1.95 and $40 \mathrm{~cm}$ for 
length, width and depth, respectively. While, the dimensions of the wage brick entries are 2.10, 1.80 and $40 \mathrm{~cm}$ for length, width and depth, respectively. Also there are different types of mortar, which joining both the limestone and wage brick.

The new part of the wall is formed of an irregular line of limestone and wage bricks having height about $2.90 \mathrm{~m}$, it has a group of vertical and straight cracks and some corroded limestone and wage brick courses. Impact of humidity and salts crystallization are present, may be according to the humidity state and the nature of the area which is threatened always by the underground water (Figure 9).
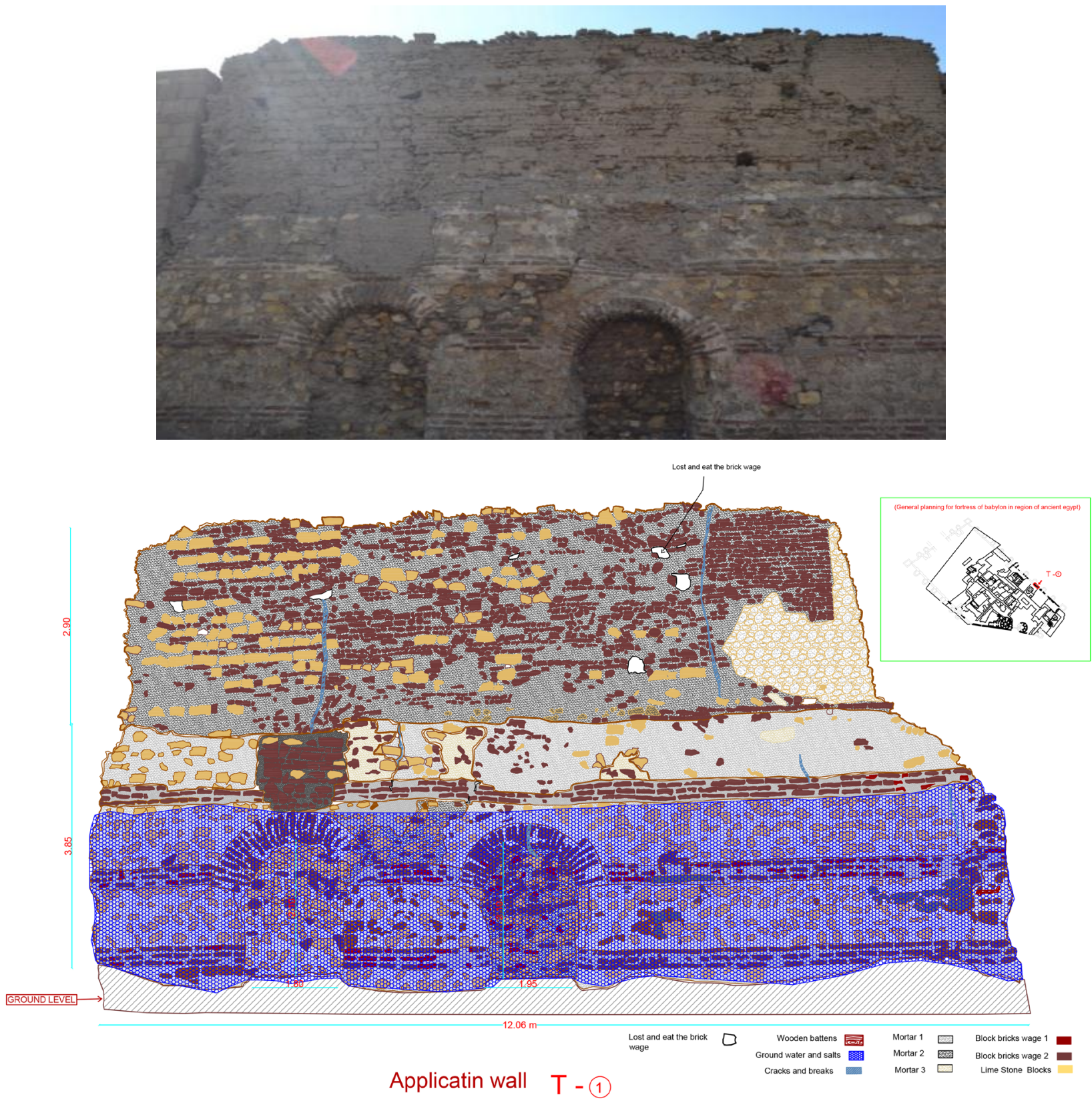

Figure 9. North-eastern wall next to the Jewish temple from the original part of the Babylon. 


\subsection{The Northern-East Frontage}

Behind the application wall: This wall has ancient and new parts. The ancient one has (six) sections of limestone, each section consists of (five) rows and (five) sections of wage bricks, every section has (3) lines attached with lime mortar to connect the lines together. Its width is about $16.85 \mathrm{~m}$ and height about $6.53 \mathrm{~m}$. Also has irregular dimension with a crack in the (3) first sections across the wage bricks and limestone and a wooden strain in the third section. The new part is formed of some lines of wage bricks and having height about $1.86 \mathrm{~m}$ and width about $14.50 \mathrm{~m}$. this part isn't irregular with 3 vertical separated with a wooden strain (Figure 10).

Our present architectural documentation work of the Babylon includes the walls and towers of the fortress; the northern roman tower underneath the Greek Church (Mary Girgis), the second round tower located in front of the Coptic Museum, the two towers of the Hanging Church, the south tower next to the tombs, and the remaining walls existing at the north-east and north-west next to the Jewish Temple, where Figure 11 represents the degradation maps of the northern and Easter walls next to the Jewish temple.

\section{State of Preservation}

The Babylon of Egypt had been flooded in it lower level for a long time until up to 2002, when a massive program of underground tunnels and well-points for dewatering parts of Old Cairo was completed. The increase rise of the water table may be attributed to the construction of the metro line (Mar Girgis Station) passing the old Nile bed, creating a diaphragm.

The Roman Babylon suffered from sustained serious damages on the surface of the stone walls at their lower levels due to the long term flooding. Fully penetrating cracks at the walls may resulting mainly because of the old settlements and partially due to the dewatering while corner of stones had been removed at

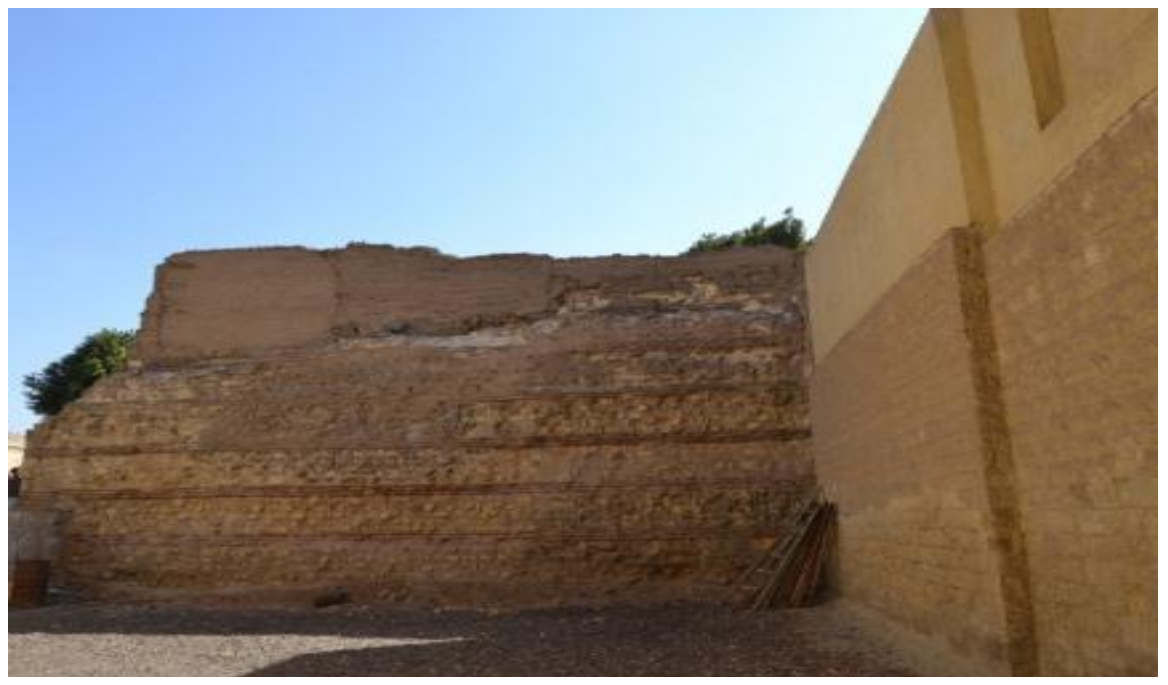

Figure 10. The North western wall of the fortress of Babylon. 


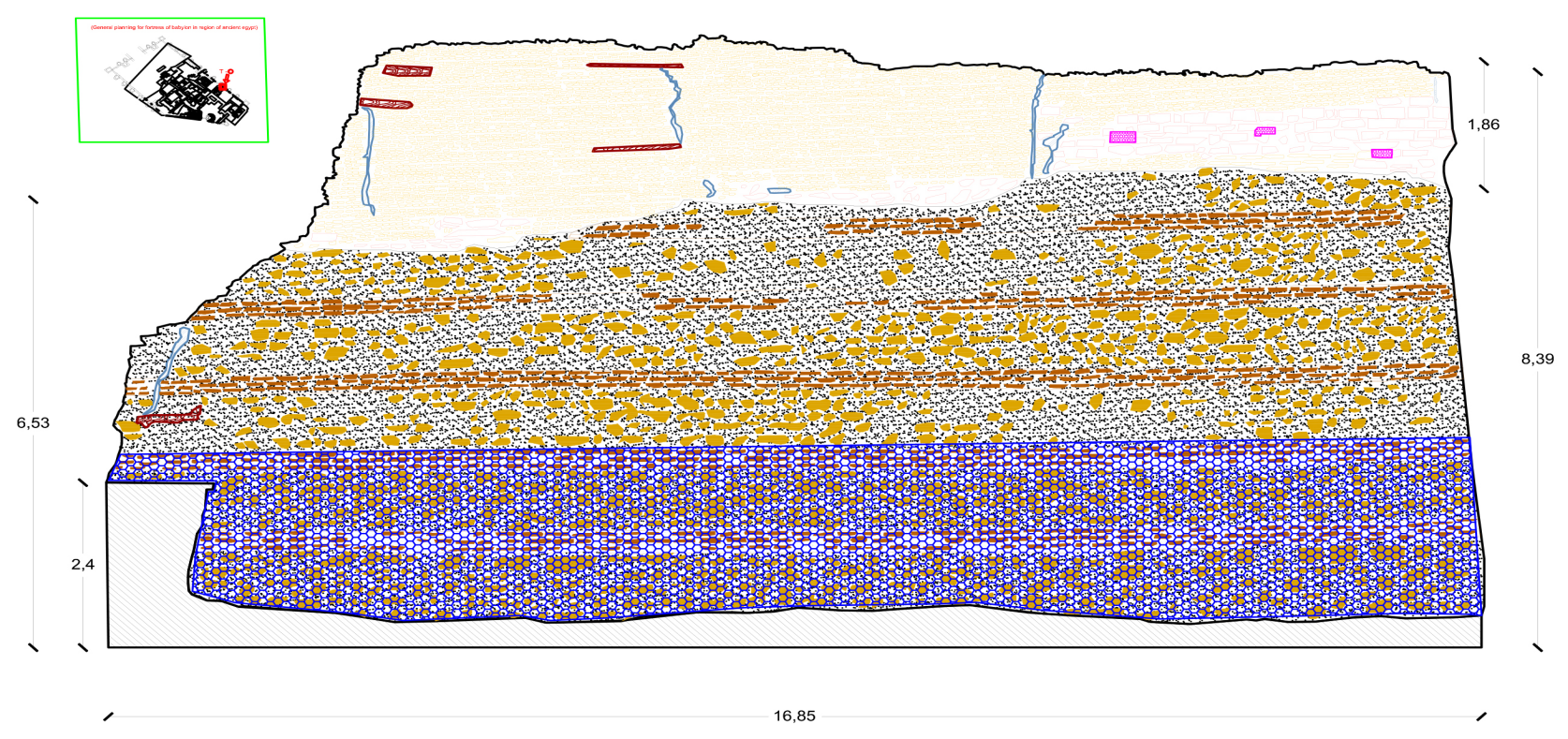

North - west facade $T$-(1)
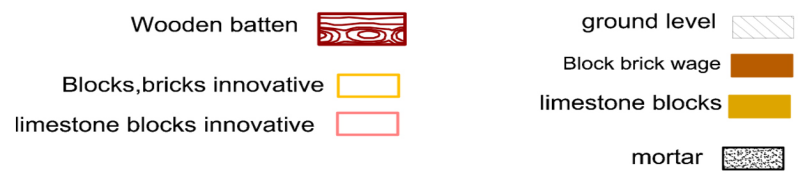

Figure 11. Degradation map of the North western wall of the fortress of Babylon.

specific locations. The cracks at the towers and walls were stable after the dewatering as was evident from the glass markers installed. One very significant source of surface disfiguring might resulted from the fesses of bats that inhabited the tower in thousands.

Salt crystallization is one of the major causes of deterioration of porous building materials of the Babylon (the Brick and structural hydraulic mortars), strongly related to the fluctuation of the surrounding environmental parameters. The salt damage accrued either aesthetic, when salt crystallization occurring on the surface of the materials (efflorescence) and disturbs the perception of the artwork, or mechanical, when the crystals are formed below the surface (sub florescence), causing pressure within the structure of the material. Repeated cycles of dissolution and recrystallization, provoke the weakening, detachment and loss of the surface layers.

Figure 12 presents the observed main aspects of the structural deficiency of many walls and towers of the Babylon of Egypt. Cracks and fissures took places in the vertical walls. Permanent deformation of the bricks is observed in the zone of the borders and main wall of the façades. Dangers cracks appeared in some towers and separation between the façade and the radial walls are obvious. These damage forms are related to the mechanical actions in particularly the seismic hazards and geotechnical problem of the bearing soil.

Figure 13 shows some of the recorded forms of the physical and chemical 


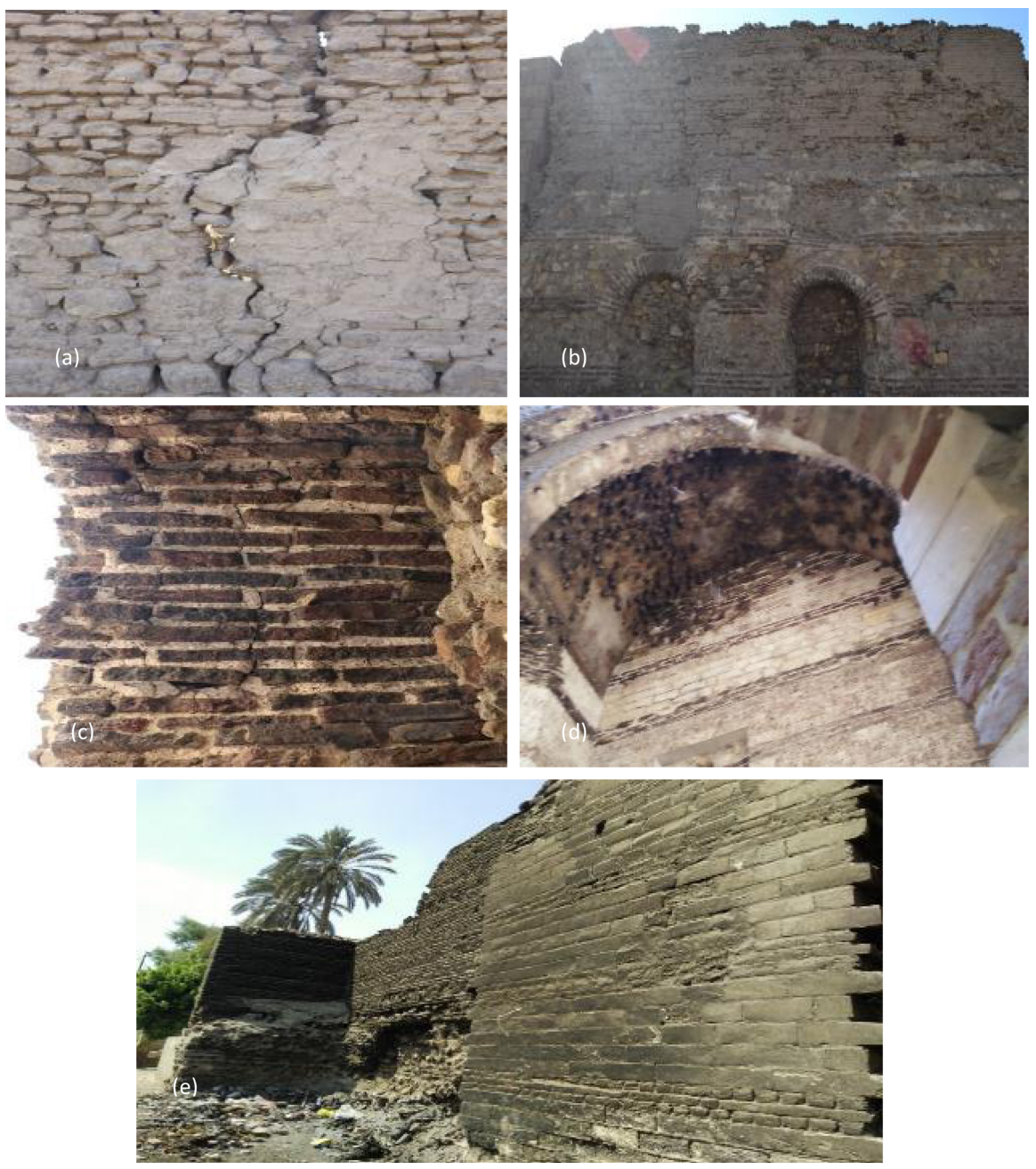

Figure 12. Structural deficiency of many walls and towers of the Babylon of Egypt: (a) cracks and fissures in the vertical walls; (b) permanent deformation of the bricks in the zone of the borders and main wall of the façades; (c) danger cracks appeared in some towers; (d) one very significant source of surface damage resulted from the fesses of bats that inhabited the tower in thousands. And (e) separation between the façade and the radial walls are obvious.

deteriorations due to subsurface water rising and salt weathering affecting the roman and byzantine bricks and the joining structural mortars.

\section{Materials and Methods}

Several laboratory examination and analyses were carried out to identify the nature of the brick and structural mortars used to build the Babylon fortress in the ancient Egypt region, which dates back to the 4th century. About 30 samples represent the construction materials (brick and mortar) were collected from the fallen fragments. Eleven thin sections were examined using polarizing light microscopy to identify the petrographic characteristics of these construction materials. XRD and XRF analyses were performed to identify the components and ratios of the elements in the installation bricks and mortars; along with the SEM 

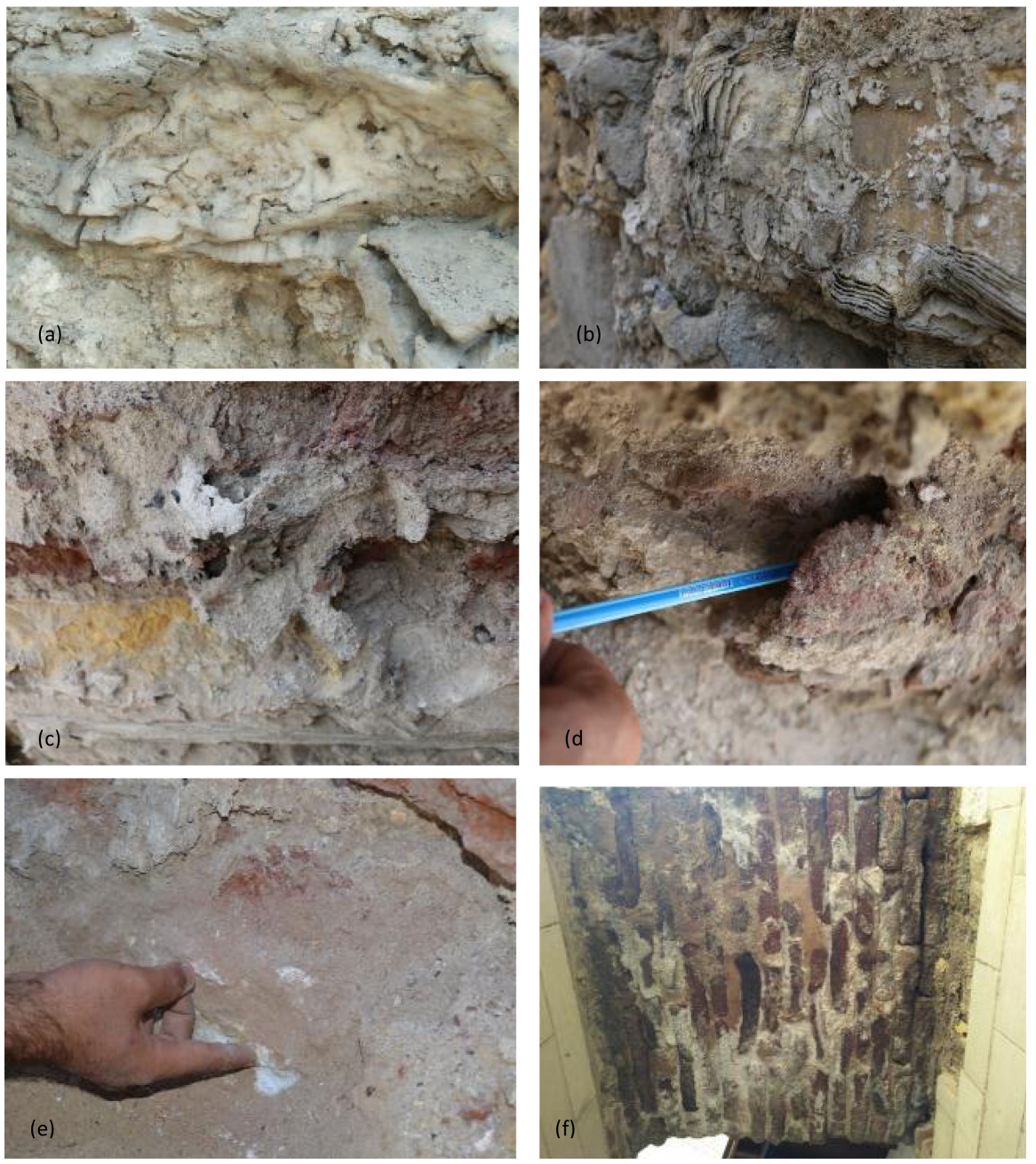

Figure 13. Physical and chemical deterioration forms due to subsurface water rising and salt weathering affecting the roman bricks and structural mortars; (a) and (b) salt efflorescence; (c), (d) and (e) crypto florescence, layers exfoliations and hard black crust formation; (f) brick and joining mortars disintegration due to salt weathering mechanisms.

equipped with EDX for microstructure examination and micro chemical analysis. XRD diffraction patterns of both the studied bricks and the mortar samples are gained through $\mathrm{Cu} \mathrm{K}$ radiation. The scanning speed is $2 \theta=1$ degree $/ \mathrm{min}$. at constant voltage $40 \mathrm{kV}$, and $30 \mathrm{~m}$ A using PW $1480 \mathrm{X}$-ray diffraction. The identification of the Constituents has been achieved using the ASTM Cards through determining the d-values of the different atomic planes and their relative intensities. Major elements (wt\%) of the studied mortar samples have been performed using X-ray fluorescence spectrometry (XRF) on a modern Wavelength Dispersive Spectrometer (Axios, WD-XRF Spectrometer, PANalytical, 2005, Netherlands). The chemical analyses were carried out adopting the ASTM specifications (ASTM C114-00 (ASTM C114-15). Scanning Electron Microscope (SEM) images were performed on JXA 840A electron probe micro analyzer, Japan.

The physical and the mechanical characteristics of the studied construction materials (bricks and mortars) were achieved. Morphology and color analysis of 
the bricks and mortars were identified by visual observation. Forty-three cylindrical specimens have been prepared from the bricks to delineate the physical and mechanical properties. Specific gravity, unit weight, water absorption, porosity and degree of saturation are the physical aspects determined. While, the mechanical characterization included the determination of the uniaxial compressive strength, elastic static modulus of elasticity and Brazilian splitting tensile strength, as well as the Non-Destructive Ultrasonic Pulse Testing to the wave velocity through the brick specimens, the dynamic Young's modulus and shear modulus (Figure 14 and Figure 15).

\section{Results and Discussion}

Our detailed study for characterizing the used construction materials (bricks and mortars) in Babylon of Egypt are given hereunder.

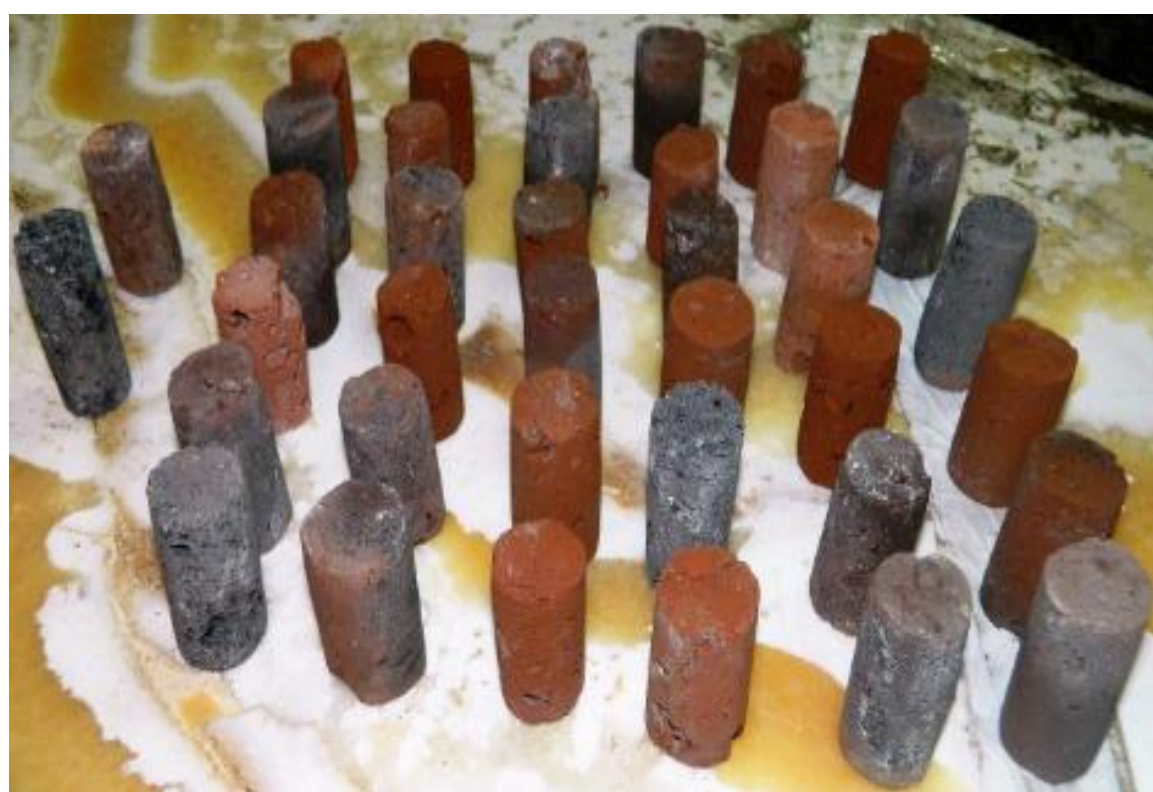

Figure 14. Investigated roman and byzantine bricks cylindrical specimens. Different colors and textures are obvious.
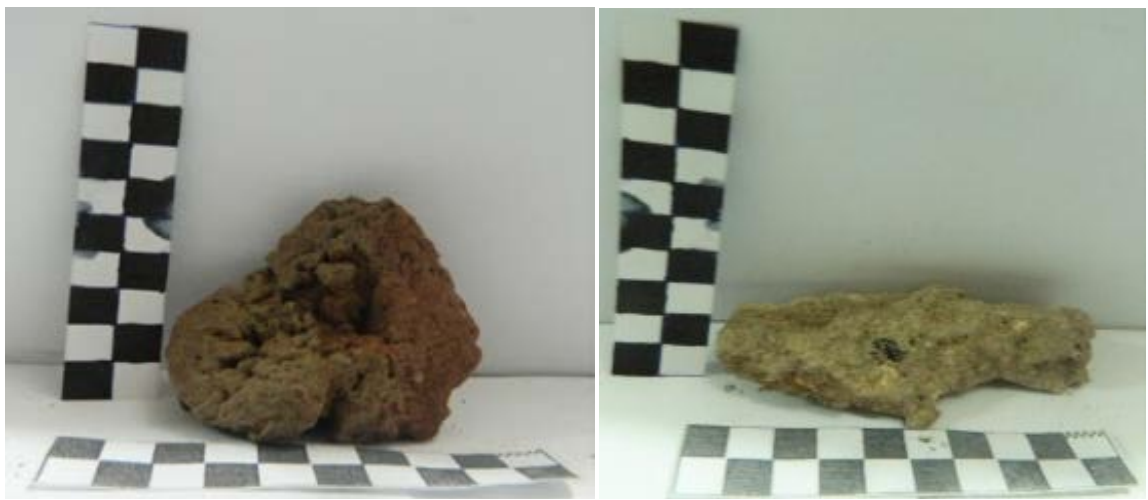

Figure 15. Investigated materials: (a) roman bricks samples; (b) joint structural mortar samples. 


\subsection{First: The Roman and Byzantine Bricks}

\subsubsection{Brick Dimensions and Colors}

The studied historical brick was manually assembled and pressed, its shape was not standard, and the upper surfaces and the concrete were rough and with curves. The shape of the brick and its dimensions are different and its color is also varied. There are nine different sizes of bricks are here recorded (Table 1).

\subsubsection{Engineering Properties}

Physical properties showed a clear difference among the studied various brick samples belonging to the one site. The values of the determined physical properties (as summarized in Table 2), the bulk density are in ranges of (1.4 to 1.8 $\left.\mathrm{g} / \mathrm{cm}^{3}\right)$, water content is in range of $(12.1 \%$ to $24.4 \%)$ and values of apparent porosity in range of (17.3\% to $43.2 \%)$. for bulk density, water absorption and apparent porosity and other physical properties had been achieved in the conservation department, Cairo university. On the other hand, Table 2 summarized the values of the determined mechanical properties; ultrasonic velocity range from (1.71 - $2.11 \mathrm{~km} / \mathrm{sec}$ ), uniaxial compressive strength range (from 1.6 - 9.2 MPa) as represent in Figure 16 and Figure 17, the static modulus of elasticity range (from 0.6 to $5.3 \mathrm{GPa}$ ), dynamic Young's modulus range from (2443 to 5353 $\mathrm{MPa}$ ), and shear modulus range (from 917 to $2007 \mathrm{MPa}$ ). Also some relationships among the determined parameters are given in Figures 18-21. Parameters obtained from UPM testing (such as ultrasonic pulse velocity, dynamic modulus of elasticity) are affected by shape/dimension of bricks, their components, and porosity and imperfections of their structure. Figure 22 and Figure 23 represent the uniaxial compression test setup and pundit ultrasonic test device, accordingly.

\subsubsection{Petrographic and Mineralogical Characteristics}

Generally, the results obtained showed that all the used materials are related to the local Egyptian materials, which had been used along time both in brick and pottery manufacture, particularly the clay materials.

Table 1. Dimensions and color of roman and byzantine bricks of the Babylon of Egypt.

\begin{tabular}{|c|c|c|c|c|}
\hline \multirow{2}{*}{ Roman and Byzantine bricks } & \multicolumn{3}{|c|}{ Dimension $(\mathrm{cm})$} & \multirow{2}{*}{ Color } \\
\hline & Length & Width & Thickness & \\
\hline \multirow{3}{*}{ Greek Tower } & 12 & 22 & $5-6$ & \multirow{3}{*}{ Lighted } \\
\hline & 11 & 17 & $5-6$ & \\
\hline & 40 & 40 & 10 & \\
\hline \multirow{3}{*}{ North Tower Round } & 12 & 25 & $5-6$ & \multirow{3}{*}{ Dark red } \\
\hline & 12 & 15 & $5-6$ & \\
\hline & 40 & 50 & 7 & \\
\hline Southern tower next to the tombs & 12 & 20 & 7 & \multirow{3}{*}{ Black Burned } \\
\hline \multirow{2}{*}{ North-East Wall } & 25 & 25 & $5-6$ & \\
\hline & 10 & 20 & $5-6$ & \\
\hline
\end{tabular}


Table 2. Engineering characteristics of Roman bricks from the Babylon of Egypt.

\begin{tabular}{ccccccccc}
\hline $\begin{array}{c}\text { Sample } \\
\text { No }\end{array}$ & $\begin{array}{c}\mathrm{Gs} \\
\left(\mathrm{g} / \mathrm{cm}^{3}\right)\end{array}$ & $\begin{array}{c}\mathrm{Wa} \\
(\%)\end{array}$ & $\begin{array}{c}\mathbf{n} \\
(\%)\end{array}$ & $\begin{array}{c}\sigma_{c} \\
(\mathrm{MPa})\end{array}$ & $\mathrm{E}(\mathrm{GPa})$ & $\mathrm{V}_{\mathrm{P}}(\mathrm{km} / \mathrm{s})$ & $\mathrm{E}_{\mathrm{dy}}(\mathrm{MPa})$ & $\begin{array}{c}\mathrm{G} \\
(\mathrm{MPa})\end{array}$ \\
\hline 1 & 1.4 & 20.1 & 27.4 & 5.8 & 1.9 & 1.71 & 2443 & 917 \\
2 & 1.5 & 10.4 & 15.7 & 6.6 & 3.3 & 1.77 & 2921 & 1095 \\
3 & 1.5 & 17.9 & 27.6 & 1.9 & 0.6 & 1.78 & 3188 & 1188 \\
4 & 1.4 & 18.3 & 25.7 & 8.6 & 1.2 & 1.79 & 3197 & 1199 \\
5 & 1.7 & 19.3 & 33.1 & 9.2 & 2.3 & 1.82 & 3537 & 1326 \\
6 & 1.7 & 20.3 & 35.5 & 4.7 & 2.3 & 1.84 & 3849 & 1444 \\
7 & 1.8 & 24.4 & 43.2 & 8.8 & 2.9 & 1.84 & 3849 & 1444 \\
8 & 1.8 & 20 & 36 & 4.05 & 1.2 & 1.86 & 4160 & 1560 \\
9 & 1.8 & 21.1 & 37.9 & 1.6 & 1.6 & 1.93 & 5072 & 1902 \\
10 & 1.4 & 12.7 & 17.3 & 7.2 & 2.8 & 1.96 & 3861 & 1448 \\
11 & 1.8 & 23.8 & 41.8 & 4.6 & 4.6 & 1.99 & 3594 & 1793 \\
12 & 1.7 & 19.1 & 31.9 & 8.6 & 2.2 & 2.02 & 3823 & 1434 \\
13 & 1.5 & 12.1 & 18.6 & 6.6 & 5.3 & 2.10 & 4120 & 1545 \\
14 & 1.5 & 21.4 & 31.4 & 4.9 & 2.5 & 2.11 & 5353 & 2007 \\
\hline
\end{tabular}

$\mathrm{Gs}=$ specific gravity, $\mathrm{Wa}=$ Water absorption, $\mathrm{n}=$ Porosity, $\sigma_{c}=$ Uniaxial compressive strength, $\mathrm{Vp}=$ primary wave velocity, $\mathrm{E}=$ static Young's modulus, $\mathrm{E}_{\mathrm{dy}}=$ Dynamic Young's modulus, $\mathrm{G}=$ Shear modulus.

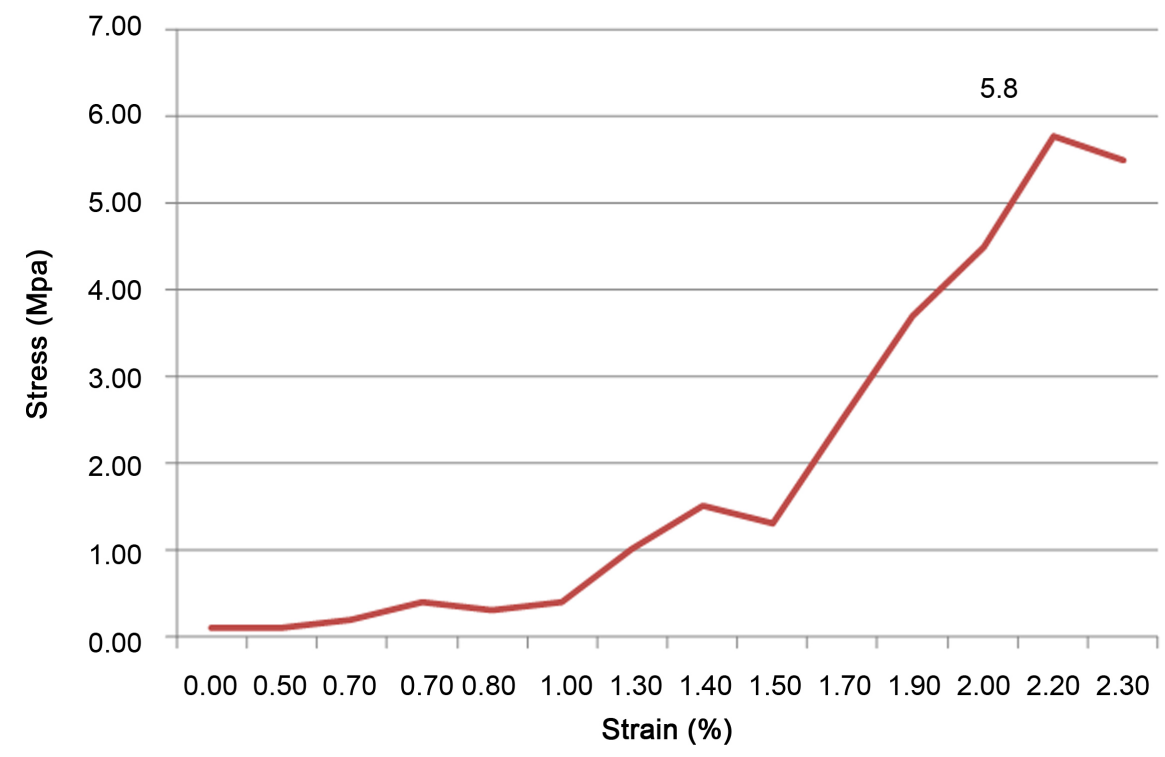

Figure 16. Uniaxial compressive stress-strain curve for the Roman bricks under investigation.

Thin section examination (Figure 24 and Figure 25) using the polarizing light microscopy revealed that the studied bricks formed mainly of quartz and feldspar grains. The quartz grains range in size from minor silt sized and very fine to coarse sand size grains. The quartz grains average (70\% - 90\%) and are generally poorly sorted, subangular to subrounded and sometimes well rounded. They are commonly mono crystalline and exhibit either uniform or undulose extinction; however some composite quartz grains also found. Amorphous silica 


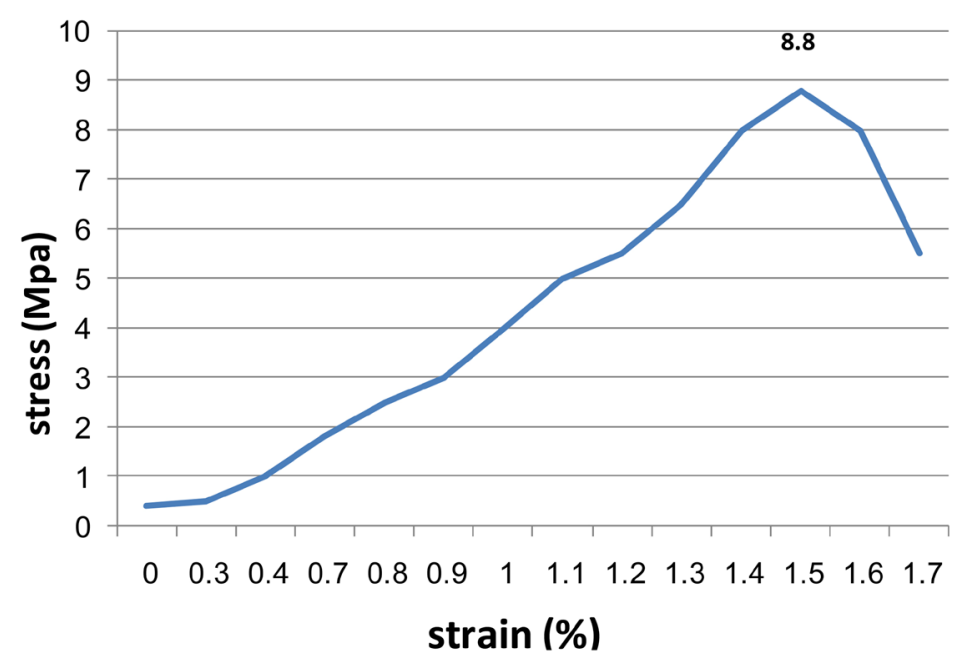

Figure 17. Uniaxial compressive stress-strain curve for the Byzantine bricks under investigation.

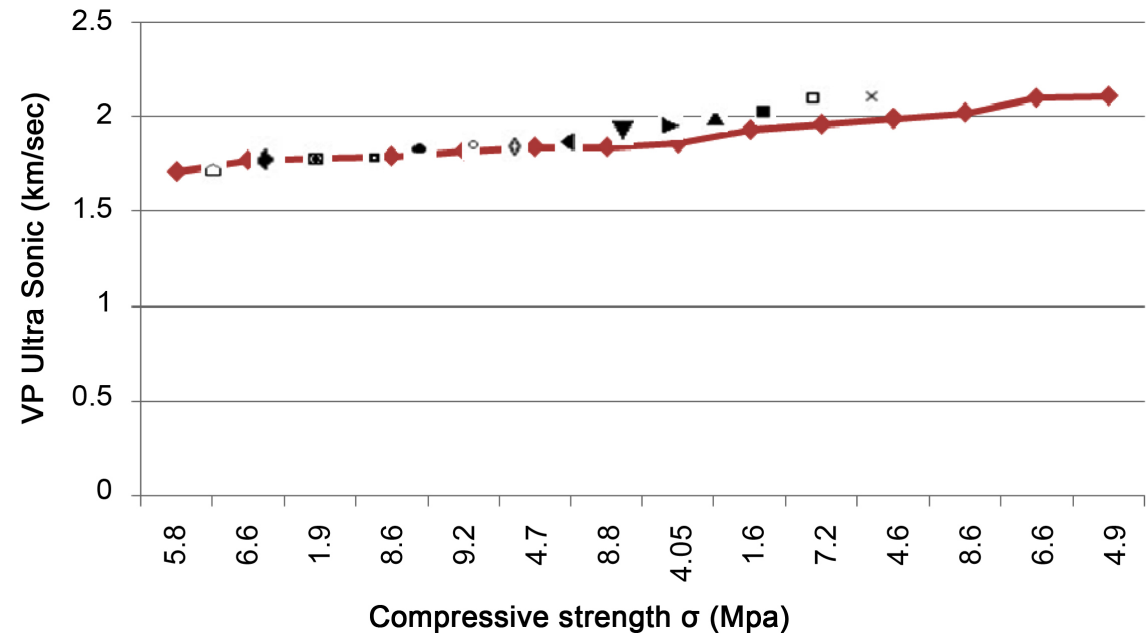

Figure 18. Ultra-sonic wave velocity versus uniaxial compressive strength of the brick under investigation.

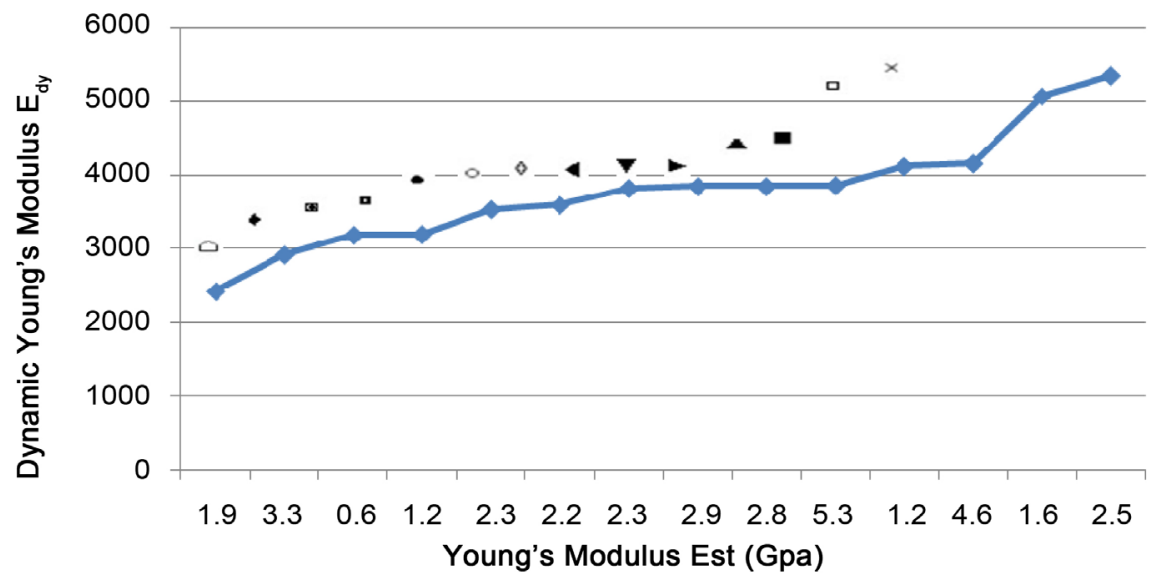

Figure 19. The static modulus of elasticity versus the dynamic modulus of elasticity of the brick under investigation. 


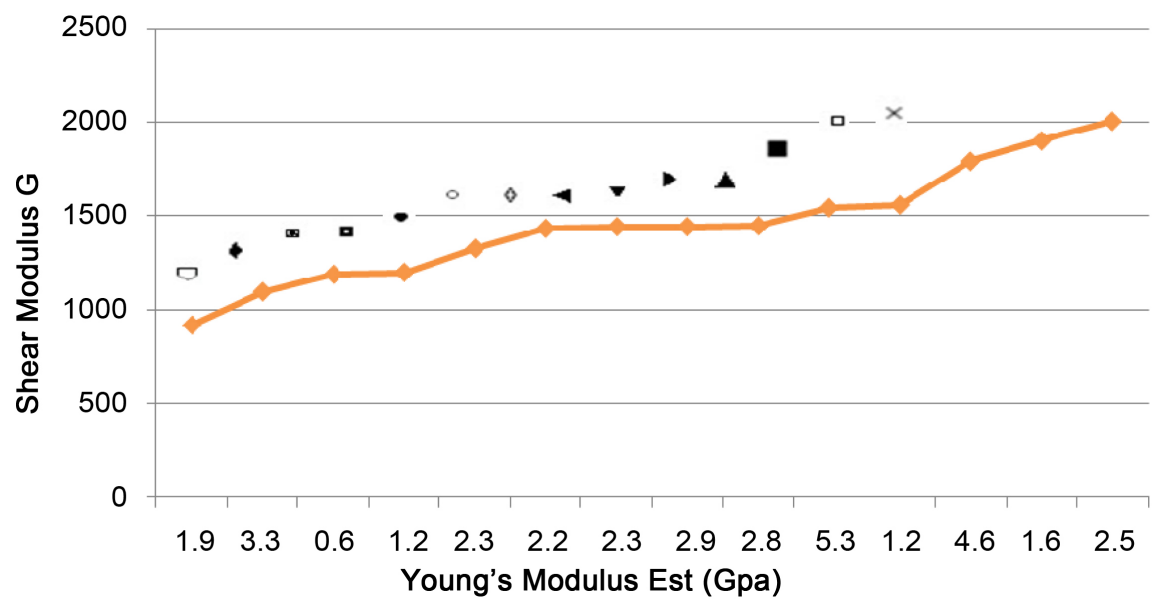

Figure 20. Shear modulus versus static modulus of elasticity of the brick under investigation.

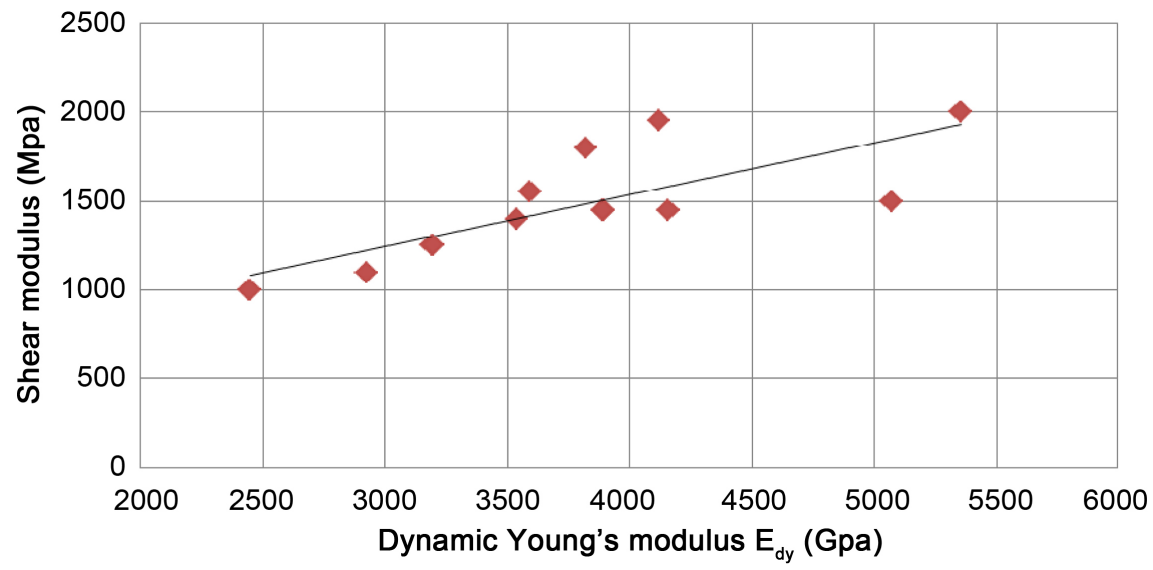

Figure 21. Shear modulus versus dynamic modulus of elasticity of the brick under investigations.

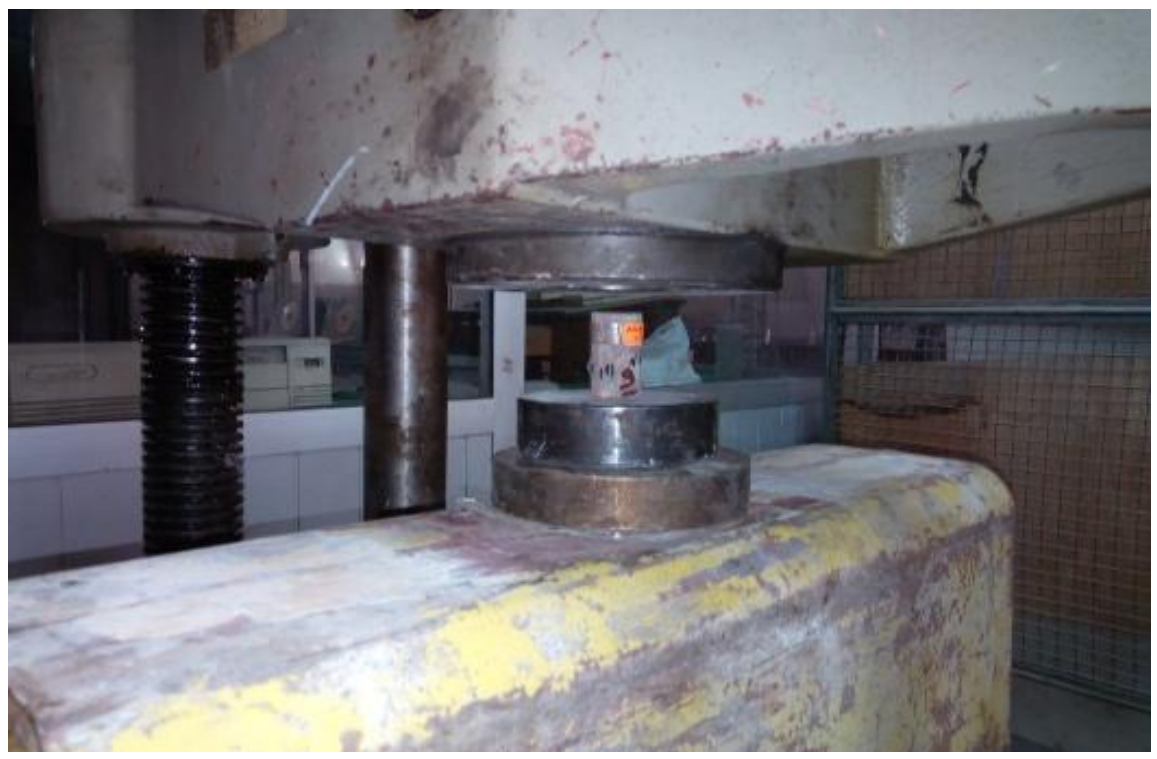

Figure 22. Uniaxial compression test on the brick cylinder samples. 

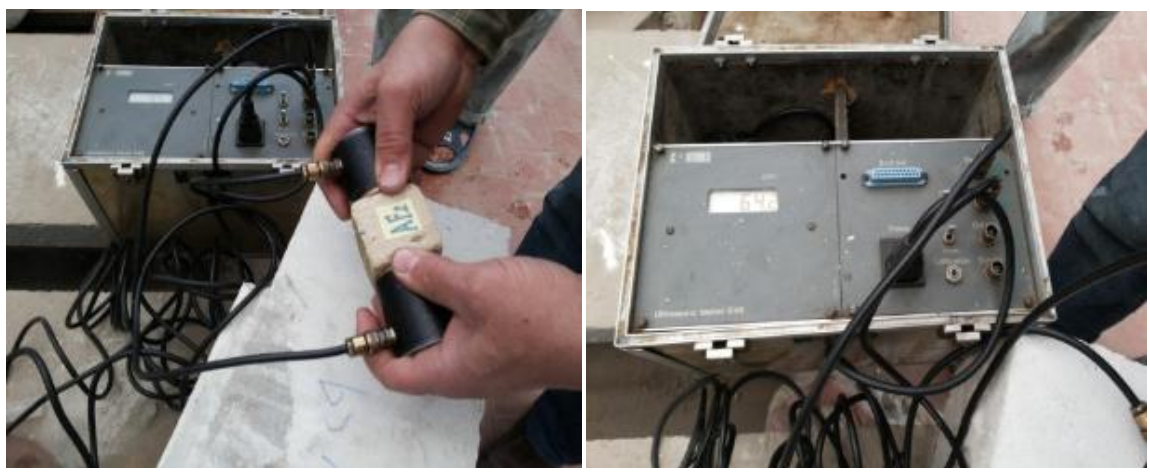

Figure 23. Non-destructive Ultrasonic pulse testing.

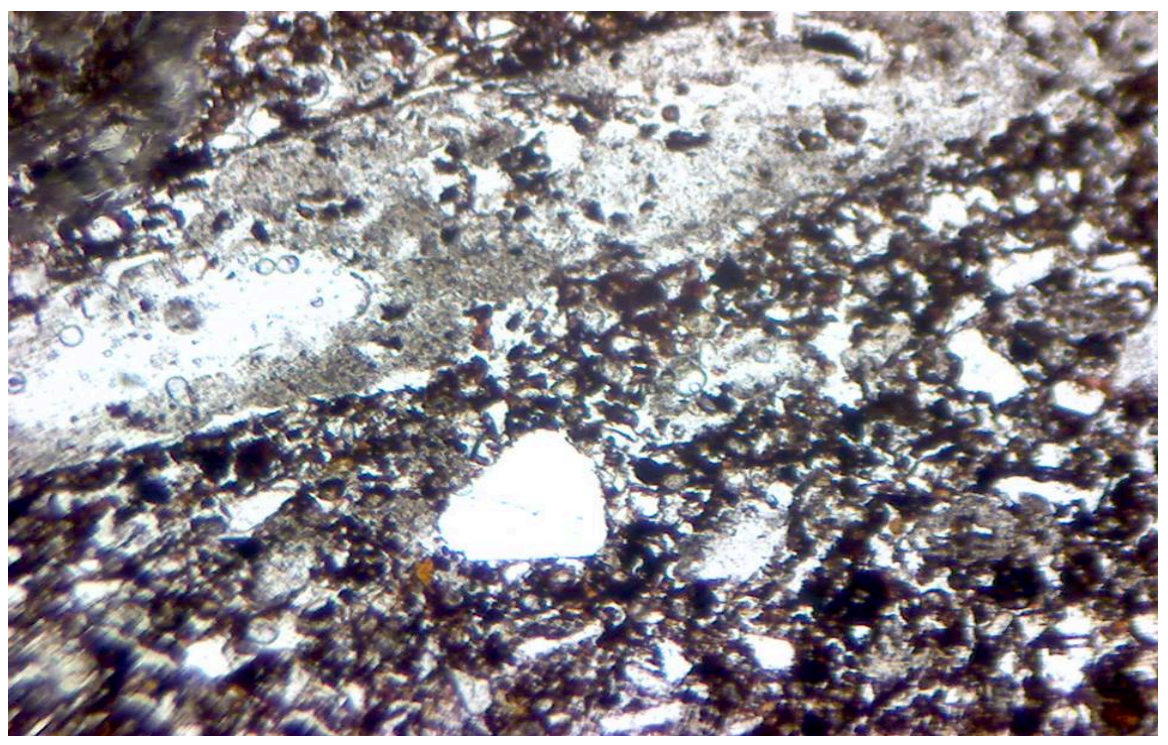

Figure 24. Quartz grains embedded in iron oxides matrix (P. P. L).

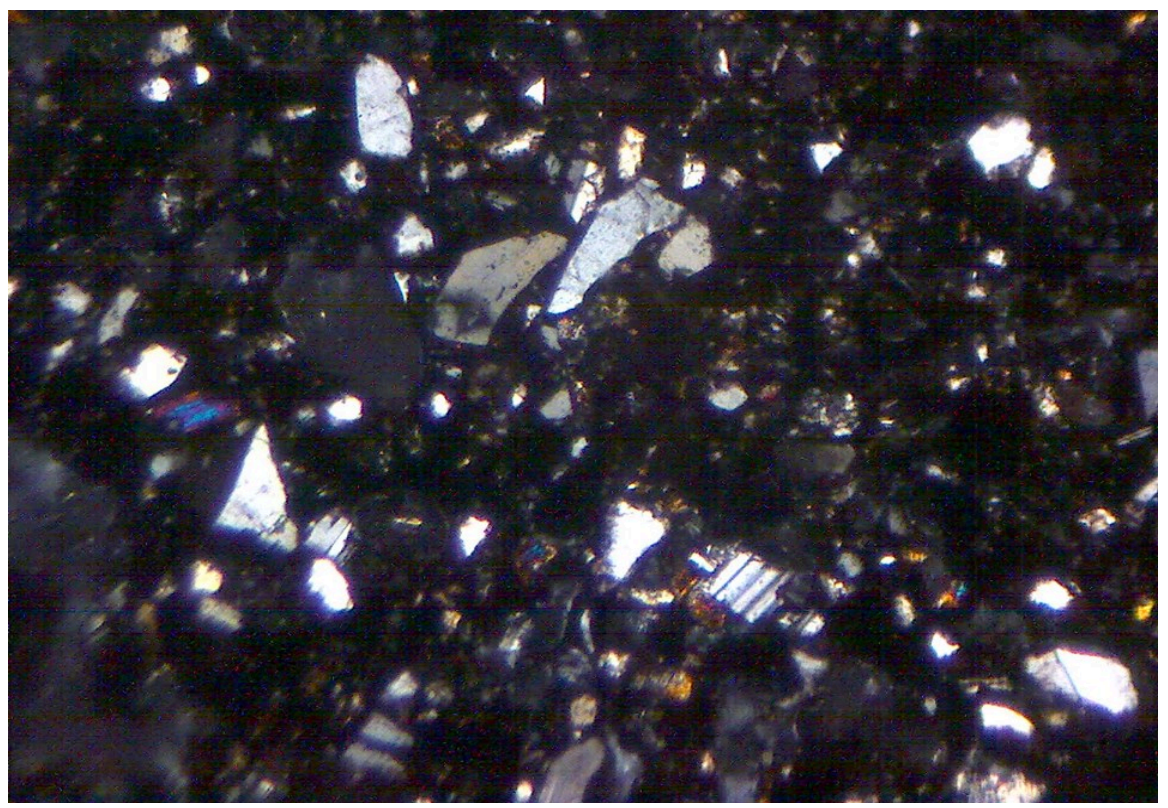

Figure 25. Quartz, mica and feldspar together with amorphous silica. 
in a form of chalcedony filling pores also observed. These quartz grains are embedded in a ferruginous dark brownish groundmass formed mainly iron oxides (hematite) and burnt clays. The iron oxides are commonly found as a dark patches or very fine material. Feldspars (average 7\%) are represented mainly by plagioclase and microcline.

The obtained XRD results (Figure 26 and Figure 27) are compatible with those of the petrographic examination. The analysis revealed that the main recorded minerals of the investigated bricks are quartz, feldspars (albite and anorthite), hematite and mullite in some samples. Mullite can consider as secondary product and is might be originated due the burning of the clays (kaolinite) at high temperature.

SEM examinations (Figure 28 and Figure 29) of the studied brick samples also, proved presence of quartz grains having various sizes ranging from fine to medium spread on a matrix of iron oxides (hematite and magnetite). Also, the morphological investigation indicate that the brick body contains different surface features, such as the wide distribution deteriorated crusts, corroded quartz grains and the presence of some large voids and micro pores, as well as, some disintegration aspects in each grain.

According to the above mentioned characteristics we can safely reported that some of the bricks were baked at sufficient temperature of more than $550^{\circ} \mathrm{C}$ indicated by the presence of the mullite that formed after kaolinite. Open burning technique was used in the production of the Babylon's bricks because some of the bricks have an indication of low firing burning. The dry weight percentage

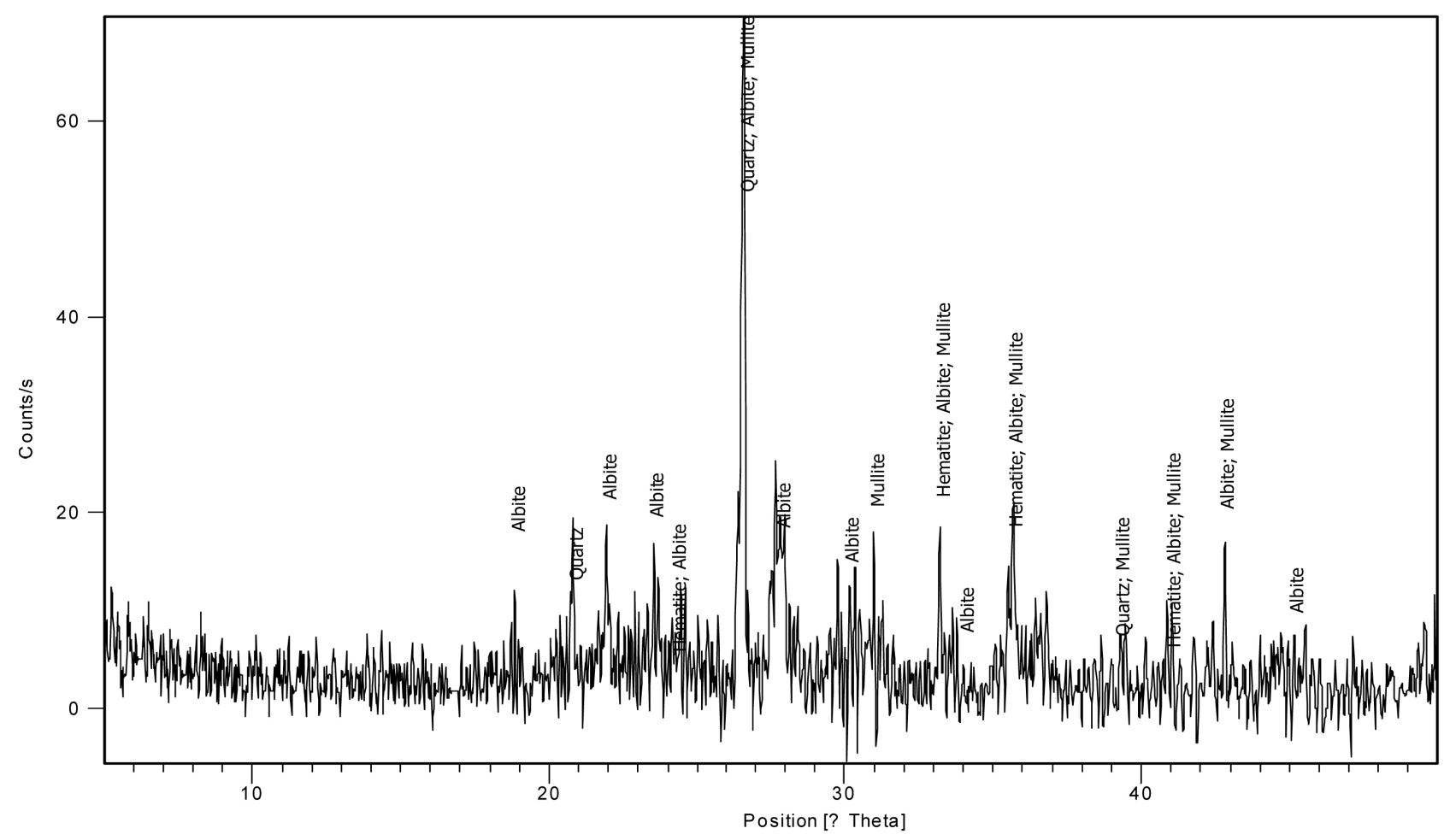

Figure 26. XRD pattern of the Roman bricks under investigations. 


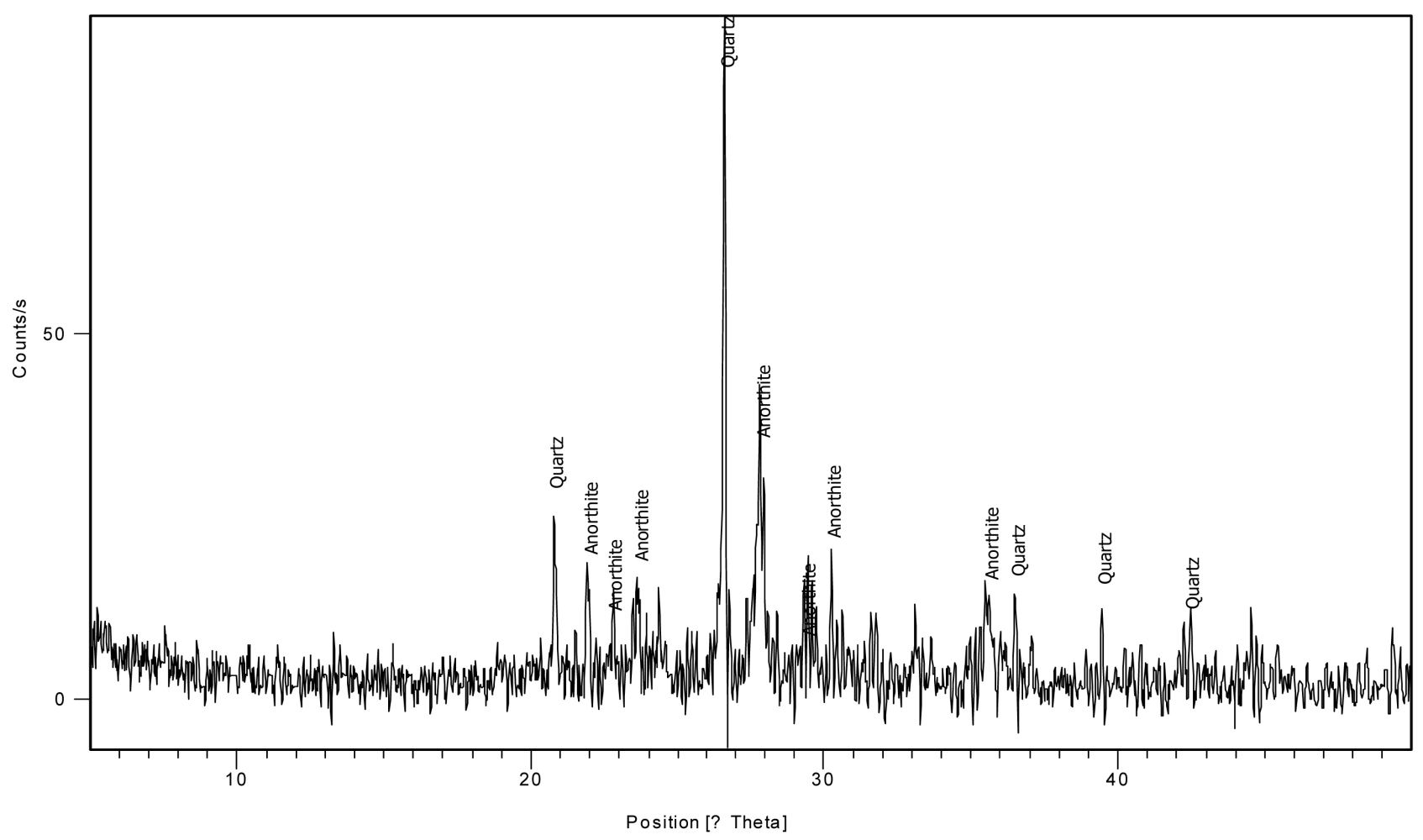

Figure 27. XRD pattern of the Byzantine bricks under investigation.

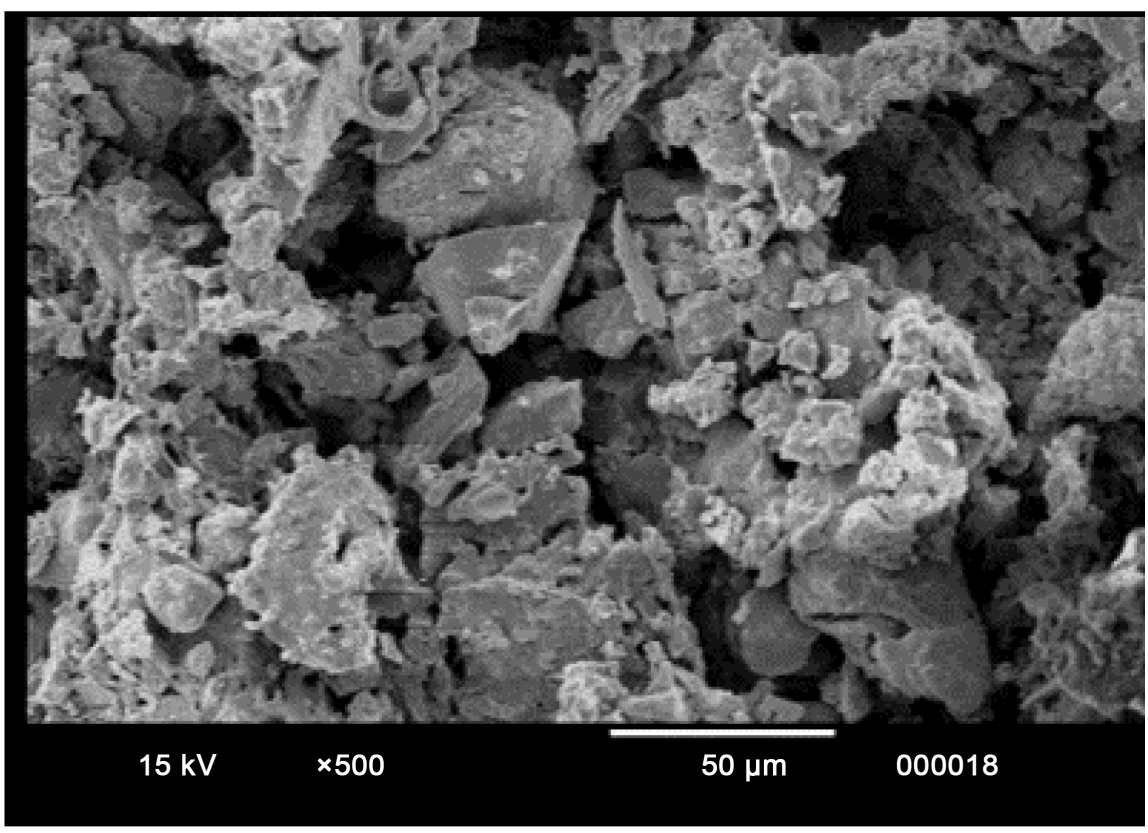

Figure 28. SEM photo micrograph showing the micro structure of the brick with quartz and iron oxides (hematite and magnetite).

graph of silica and alumina, and magnesia, as well as the lead and copper concentration graph indicate that the raw materials used to produce the ancient bricks come from local raw materials that were obtained from the surrounding area of old Cairo area. 


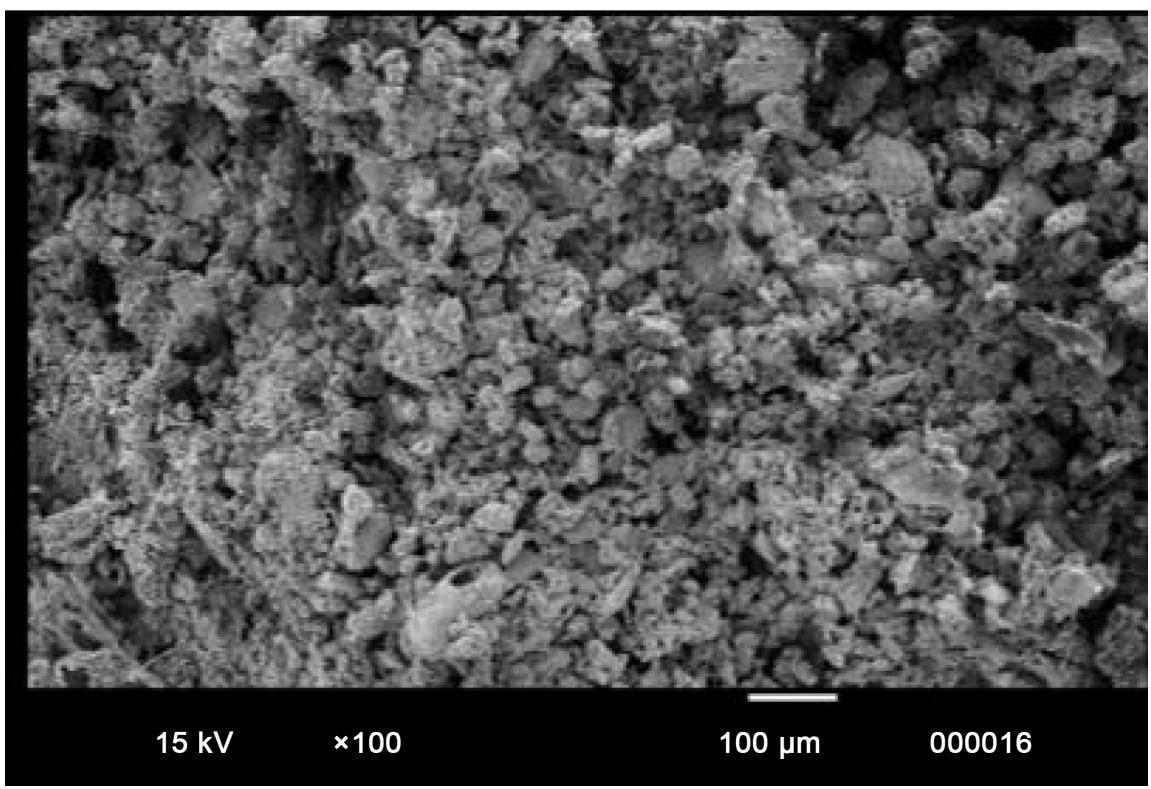

Figure 29. SEM photomicrograph showing the very fine quartz grains scattered on a matrix of iron oxides.

In this domain, it is worth mentioning that the Nile sediment was the main component of the manufacture of the roman and byzantine bricks of Babylon of Egypt. Admixture of clay and silt/sand together with straw and/or plant ash was used. They differ according to the presence of silt and the amount of the clay is stopped, especially plasticity and cohesion of clay.

\subsection{Second: The Joining Construction Mortar (Hydraulic Lime Based Mortars)}

\subsubsection{Visual Characterization}

Visual observations indicated that, the shape and texture of the joining structural mortars are dissimilar and have many inclusions and composition. The used mortars in the fortress of Babylon can be distinguished into three different types of mortars (named as M1, M2 and M3), They are differ in shape and color in addition to the difference in the internal structure. Mortar 1 (M1) is yellowish white and coarse grained, mortar 2 (M2) has a dark grey and is of medium grained and mortar 3 (M3) is coarse grained with light gray color.

\subsubsection{Petrographic and Mineralogical Characteristics}

For petrographic examinations the collected mortar samples (M1-M3), three thin sections were prepared. The study showed that the investigated mortars (Figures 30-32) consist of medium to coarse, sub rounded to rounded mono crystalline quartz grains as well as some Feldspars, which are the main components of the sand used for mortar preparation. These grains are embedded in a ground mass made up of very minute crystals of microcrystalline carbonate ooze (micrite), as well as large granules of calcite, with a small percentage of gypsum in some samples. Aggregates of the red bricks (Quartz + iron oxides) as well as 


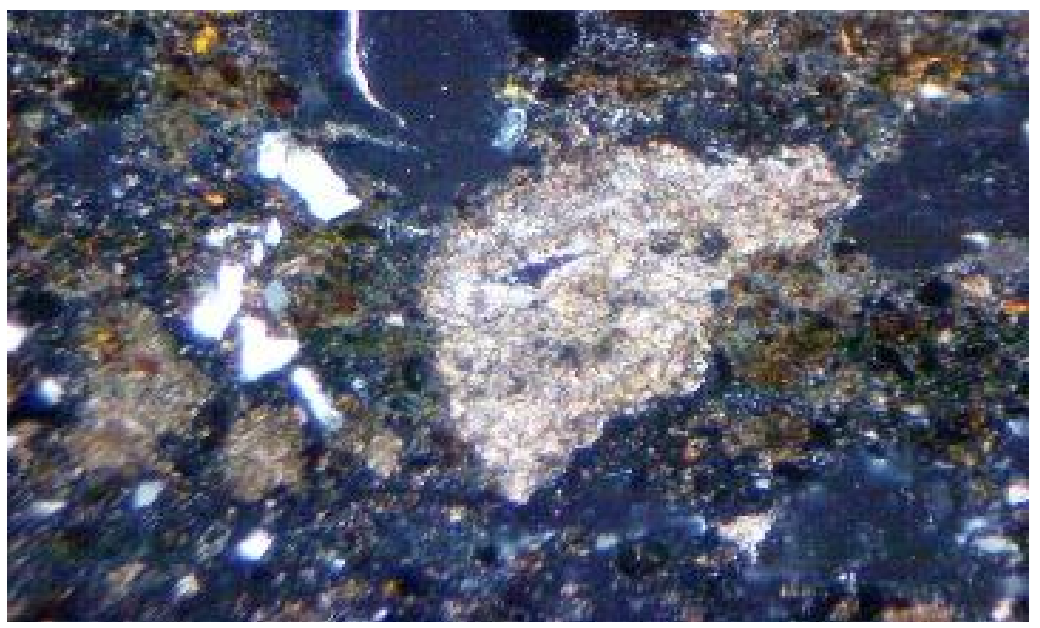

Figure 30. Microscopic photograph showing the quartz granules and gypsum in a ground of lime (P.P.L, sample M1).

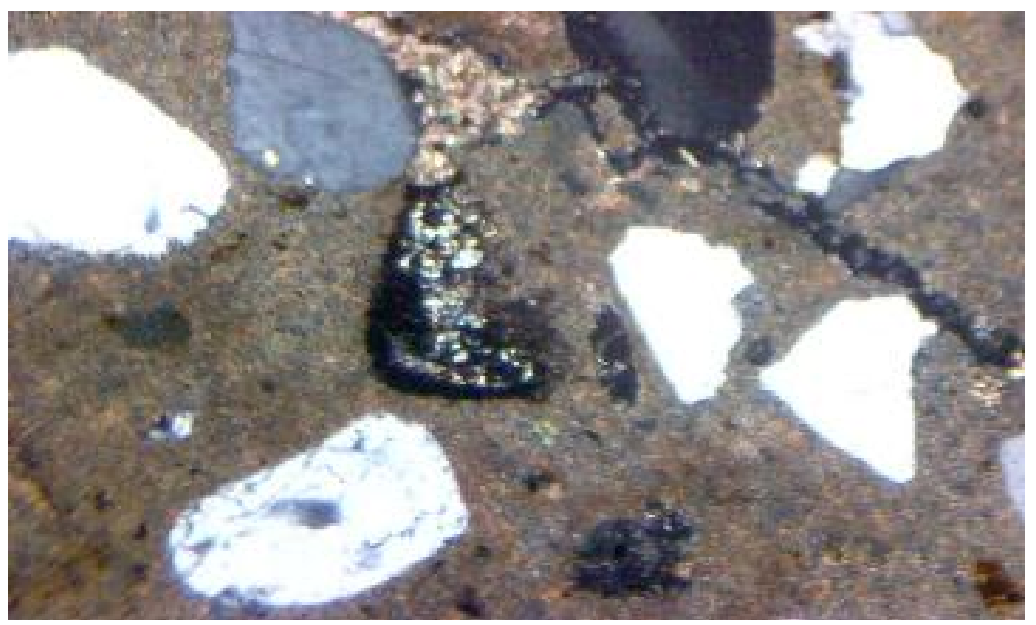

Figure 31. Microscopic photograph showing aggregates of lime and ceramic brick together with quartz grains (C.N, sample M2).

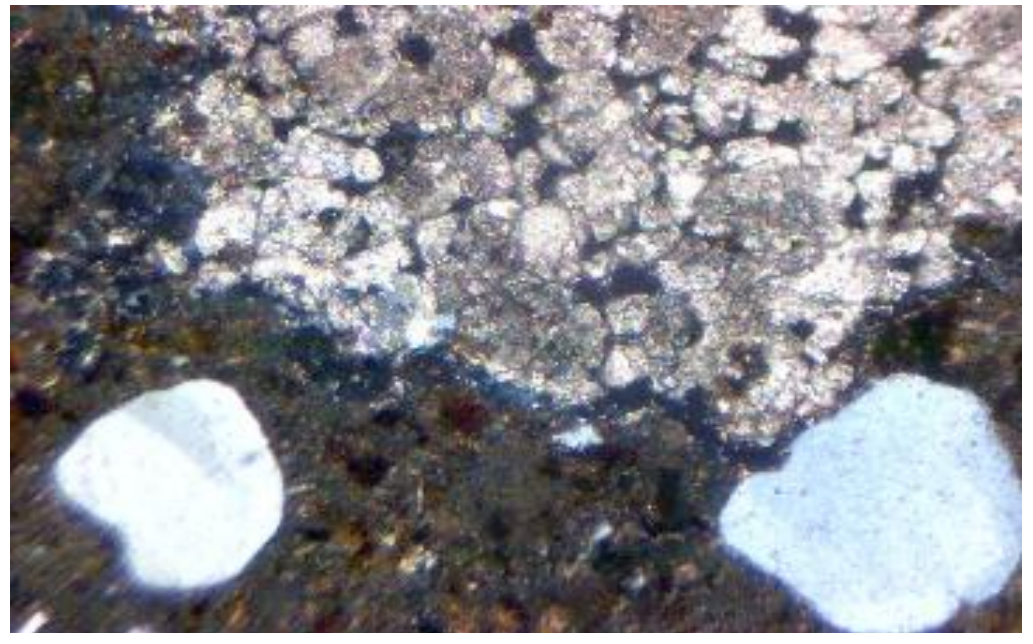

Figure 32. Microscopic photograph showing coarse limestone aggregate, quartz and black (carbon) fractions (P.P.L., sample M3). 
limestone fractions are also recorded, and may be added to the mortar as a filler material. Dark to black spots also observed may be related to the addition of burnt dust (furnace slag) during preparation presses.

Etching a hand specimen mortar sample with dilute $\mathrm{HCl}(10 \%)$, it was clear to recognized the main materials used in the mortar, Figure 33. Such include small flakes and aggregates of limestone red brick as well as sand grains and lime, which corroborate the petrographic investigations.

Regardless of the natural adhesion between the brick and lime mortar, the chemical reaction between the hydraulic mortars and the Silica amorphous from the burnt brick at low temperature helps the strong bond between the brick and mortar.

XRD results (Figure 34 and Figure 35) for the studied mortar samples (M1-M3) revealed that quartz, calcite and gypsum are the main constituents that exhibiting different proportions for each sample. These constituents are related to the used raw material (sand, lime and gypsum) during manufacture, which is in accordance to the petrographic results. Difference proportions of the sand, lime and gypsum in one sample rather than to the other may related to the nature of the collected samples. Halite $(\mathrm{NaCl})$ is recorded in all the investigated mortars. It is a secondary product resulted due the effect of subsurface seepage saline water, which is one of the causes of decaying as indicated before. Mixing ratios of lime and sand in the mortar give it a kind of elasticity and degree of smoothness and more porosity. Adding gypsum to the mixture of the mortar might be to increase the speed of the process of doubt.

\subsubsection{Chemical Composition}

The obtained chemical analysis for the major elements (Wt\%) using XRF are

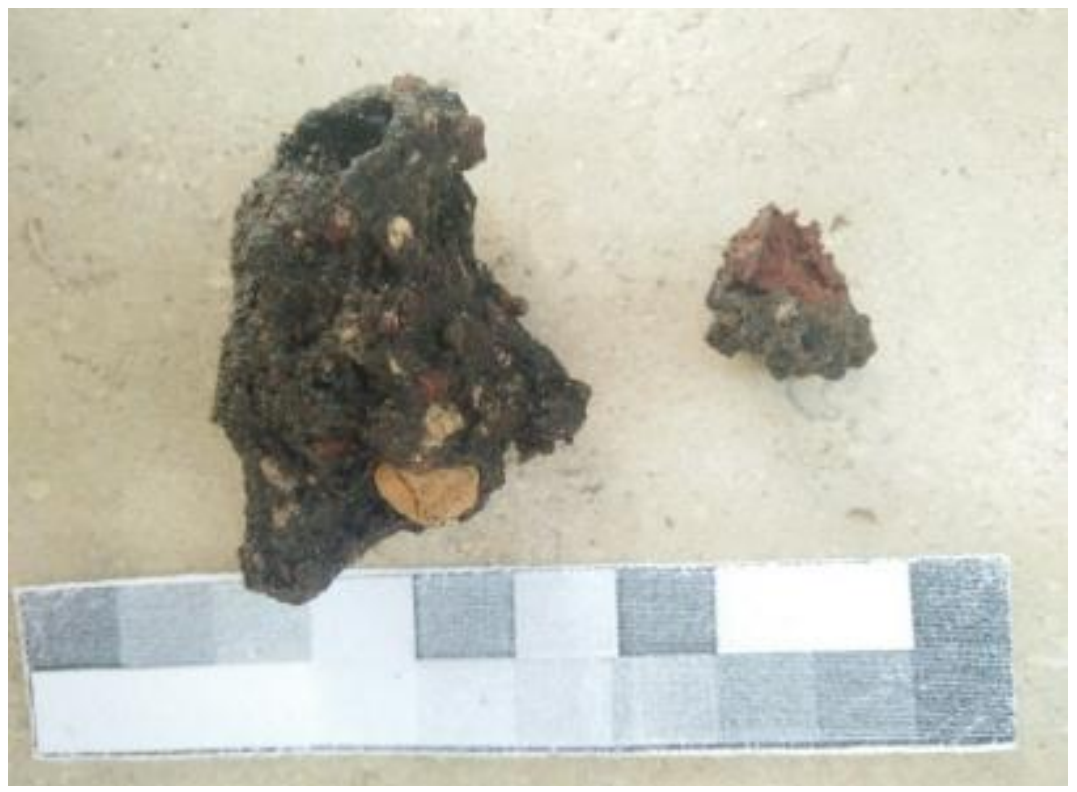

Figure 33. Mortar sample after etching by dilute HCL, Note that: limestone, brick and furnace slag fractions are detected. 


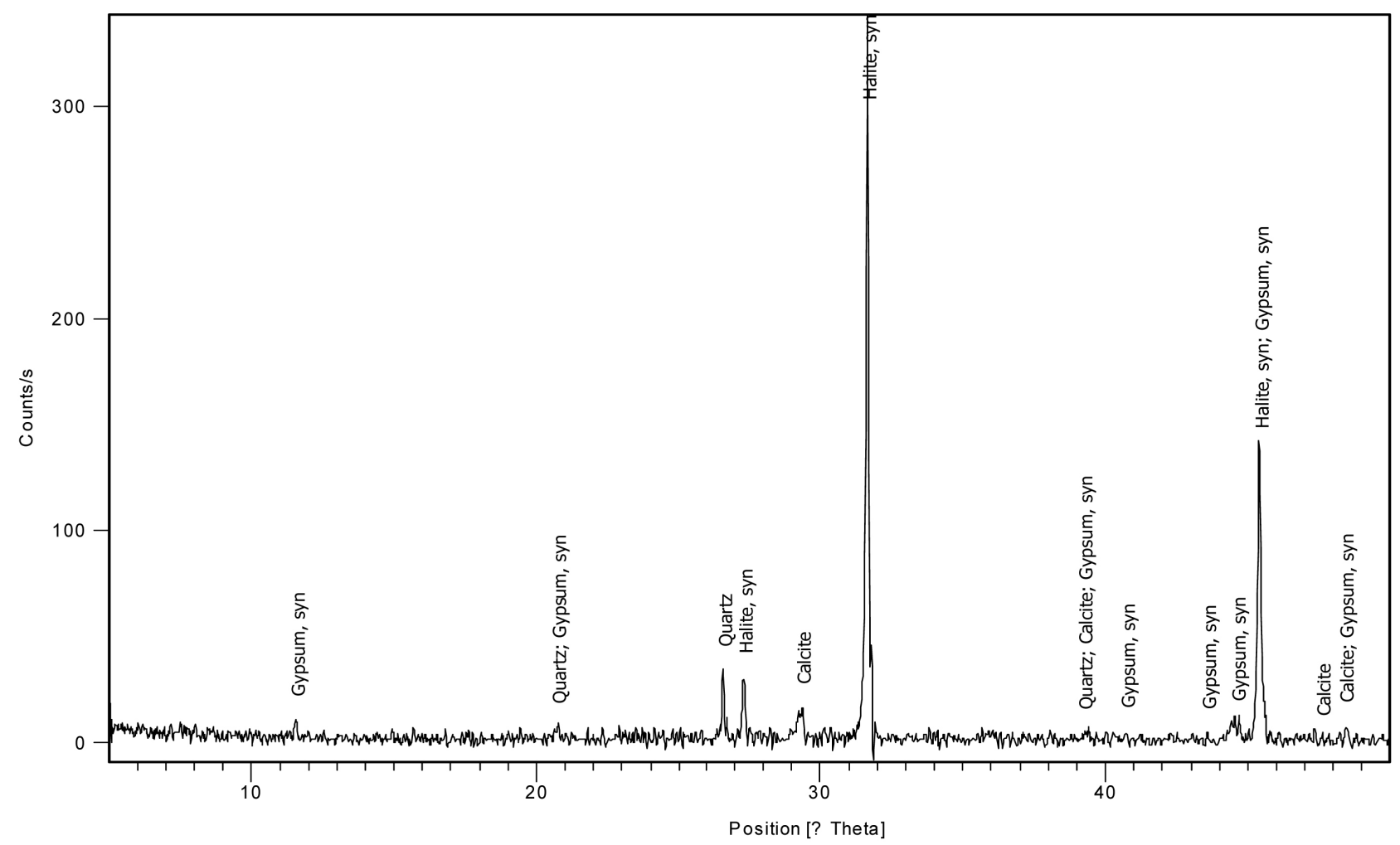

Figure 34. X-ray diffraction pattern of structural mortars from Babylon of Egypt M2.

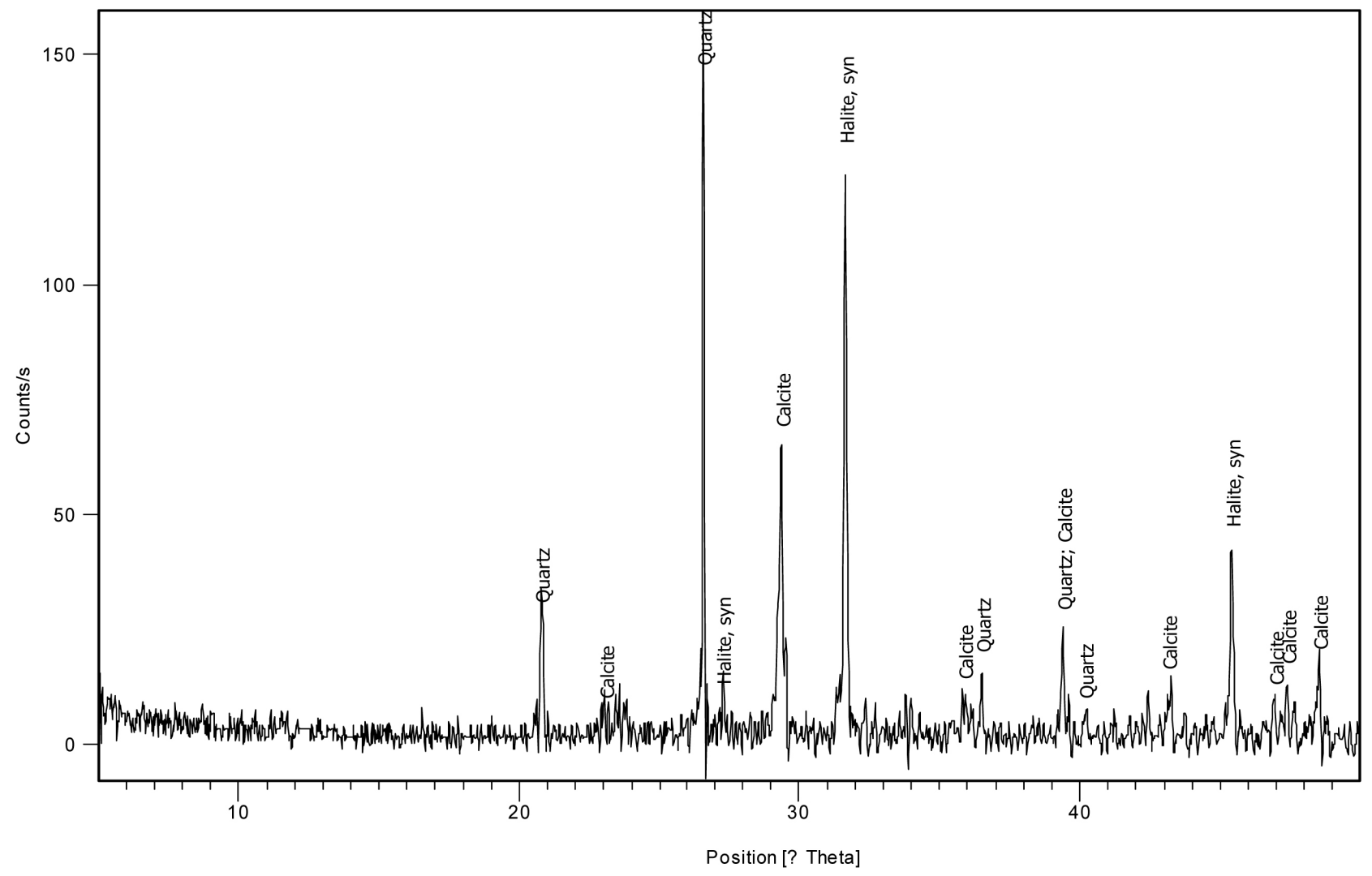

Figure 35. X-ray diffraction pattern of structural mortar from Babylon of Egypt M3. 
listed in Table 3. A glance for Table 3, it can be deduced mortar samples are of high calcium $(\mathrm{Ca})$ content. Percentage of $\mathrm{Ca}$ reflects its present as carbonate (mainly calcite). The remarkably higher value of calcium in mortar reflects the higher amount of the mineral calcite $\left(\mathrm{CaCo}_{3}\right)$ present. The sulpher $(\mathrm{S})$ content is too small to match with the content of Calcium (Ca), reflecting that less amount of gypsum and much of Ca present as carbonate (calcite). Such may corroborate that thin limestone flakes was added as filler materials during the preparation of the mortar. This is in accordance with the results obtained from the visual observation and SEM investigation. The contents of $\mathrm{Na}$ and $\mathrm{Cl}^{-}$are of high values. Higher values of both $\mathrm{Na}$ and $\mathrm{Cl}^{-}$reflecting presence salts and this can be attributed to the contribution of the mineral halite (Sodium chloride, $\mathrm{NaCl}$ ). Such is in harmony with XRD interpretation (Figure 34 and Figure 35). The content of $\mathrm{Si}, \mathrm{Al}$ and $\mathrm{K}$ is related to the composition of the sand used in mortar preparation (mainly quartz and feldspar, microcline). As shown in Table 3.

\subsubsection{Morphological Description by Scanning Electron Microscope "SEM"}

The morphological description by SEM showed that, the grains of Quartz, Lime and Gypsum pellets within the mortars. This corresponds to the results of XRD, as shown in Figure 38. The examination indicated the presence of alumina, silica, breaking of bricks and lime aggregates inside the mortar blocks. This indicates that this mortar is hydraulic lime based mortar and this corresponds to the results of the XRD. The SEM observations indicated that there is relatively leaching of calcium from the binder due to the physiochemical actions (e.g. the ground water table and acid rains) which decreased the alkalinity and strength and increased the sorptivity of this lime mortar. The lime binder becomes less hydraulic but having the highest leaching resistance, some observations indicated the presence the intensive presence of Halite inside the mortar composition. Also the presence of Carbon and residues of organic matter inside the mortar composition was obvious (Figures 36-44).

\subsubsection{Qualitative Energy Dispersive X-Ray Microanalysis}

Energy dispersive X-ray spectrometry (EDS) is a powerful tool for research studies on building materials in particularly the structural mortars. Elemental quantification contained in the hydraulic lime mortar microstructure can be performed at an excellent spatial resolution. Figure 42 and Figure 43 show the use of brick fragments in the mortar as a filler or coarse aggregates, and in the

Table 3. Major element composition (Wt.\%) of the studied mortars.

\begin{tabular}{lccccccccccccc}
\hline No & $\mathrm{Si}(\%)$ & $\begin{array}{c}\mathrm{AL} \\
(\%)\end{array}$ & $\begin{array}{c}\mathrm{Fe} \\
(\%)\end{array}$ & $\begin{array}{c}\mathrm{Ca} \\
(\%)\end{array}$ & $\begin{array}{c}\mathrm{Mg} \\
(\%)\end{array}$ & $\begin{array}{c}\mathrm{S} \\
(\%)\end{array}$ & $\begin{array}{c}\mathrm{Na} \\
(\%)\end{array}$ & $\begin{array}{c}\mathrm{K} \\
(\%)\end{array}$ & $\begin{array}{c}\mathrm{Ti} \\
(\%)\end{array}$ & $\begin{array}{c}\mathrm{P} \\
(\%)\end{array}$ & $\begin{array}{c}\mathrm{Cl} \\
(\%)\end{array}$ & $\begin{array}{c}\text { L.O.I } \\
(\%)\end{array}$ & $\begin{array}{c}\text { Total } \\
(\%)\end{array}$ \\
\cline { 2 - 11 } $\mathrm{M} 1$ & 11.4 & 1.5 & 1.1 & 30.6 & 1.8 & 2.2 & 7.8 & 4.1 & 0.1 & 0.1 & 12.2 & 26.4 & 99.70 \\
$\mathrm{M} 2$ & 12.6 & 3.26 & 3.1 & 19.4 & 2.8 & 1.9 & 10.5 & 4.0 & 0.4 & 0.4 & 13.7 & 27.4 & 99.80 \\
$\mathrm{M} 3$ & 9.27 & 1.92 & 1.8 & 30.2 & 1.3 & 1.0 & 7.6 & 4.9 & 0.3 & 0.3 & 12.7 & 28.1 & 99.81 \\
\hline
\end{tabular}




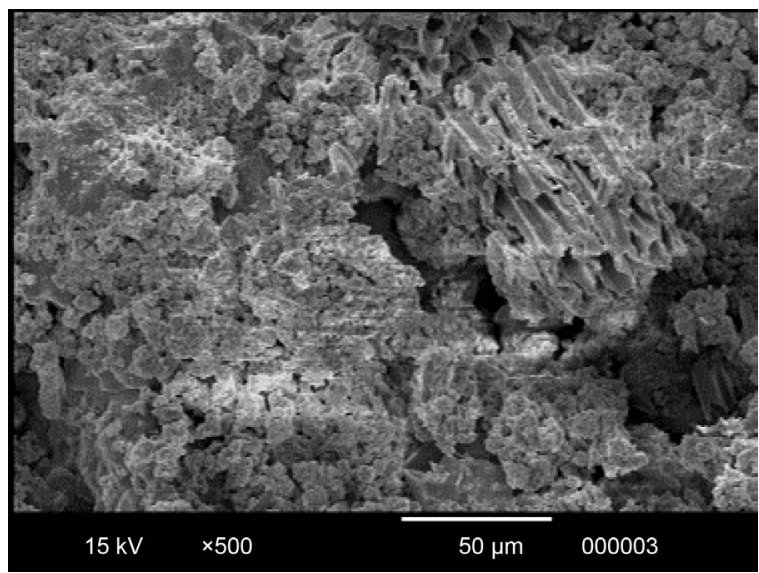

Figure 36. SEM analysis showing quartz granules of diffèrent sizes, lime granules used in the mortar and some gypsum granules and salts of the eye.

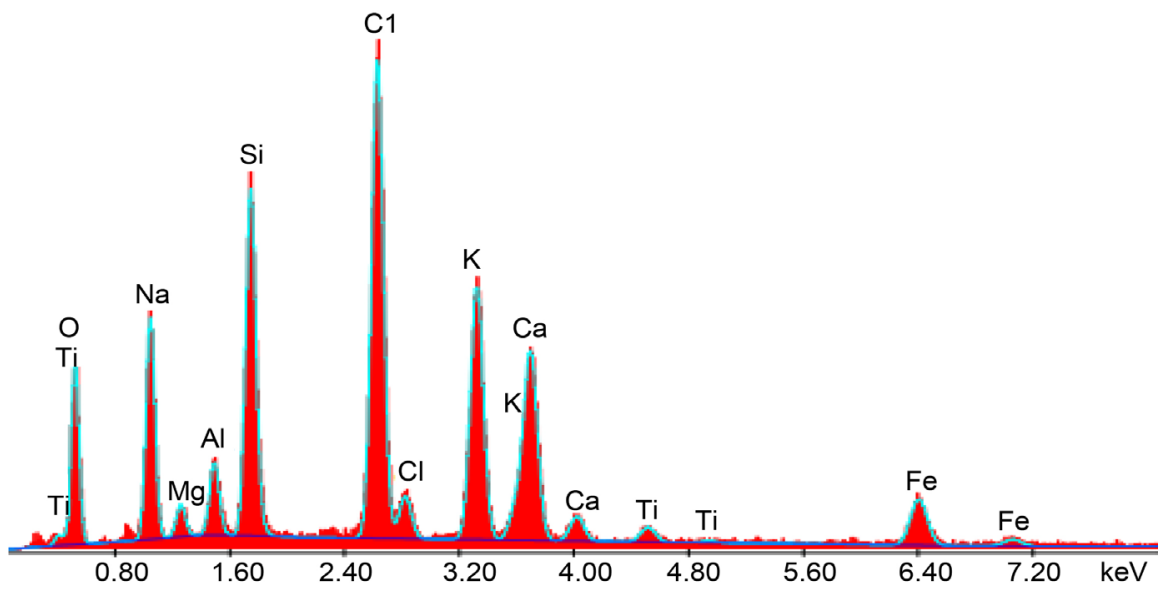

Figure 37. EDX microanalysis showing the intensive presence of Halite in the mortar composition.

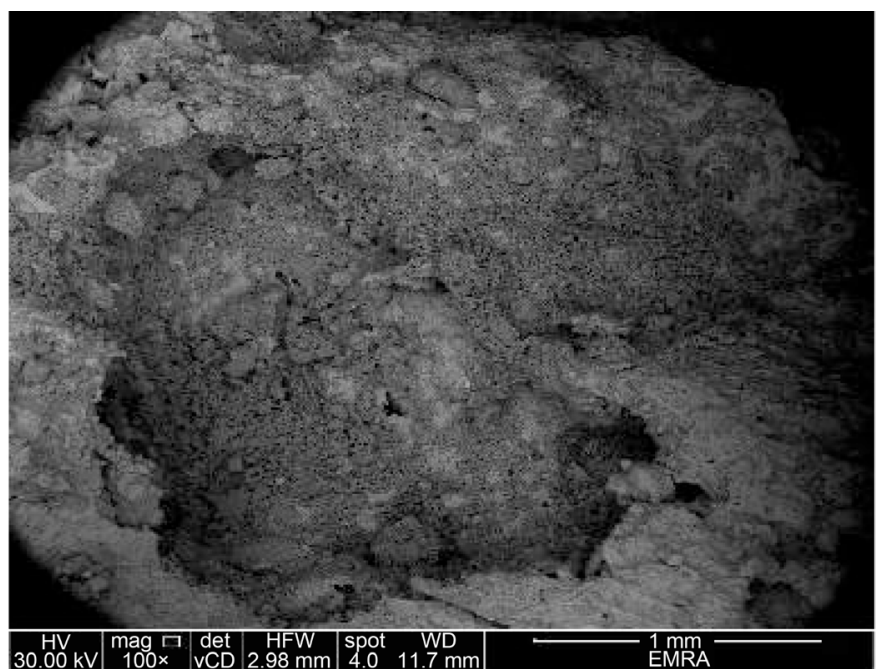

Figure 38. SEM image showing the brick aggregate fractures inside the mortar sample. 


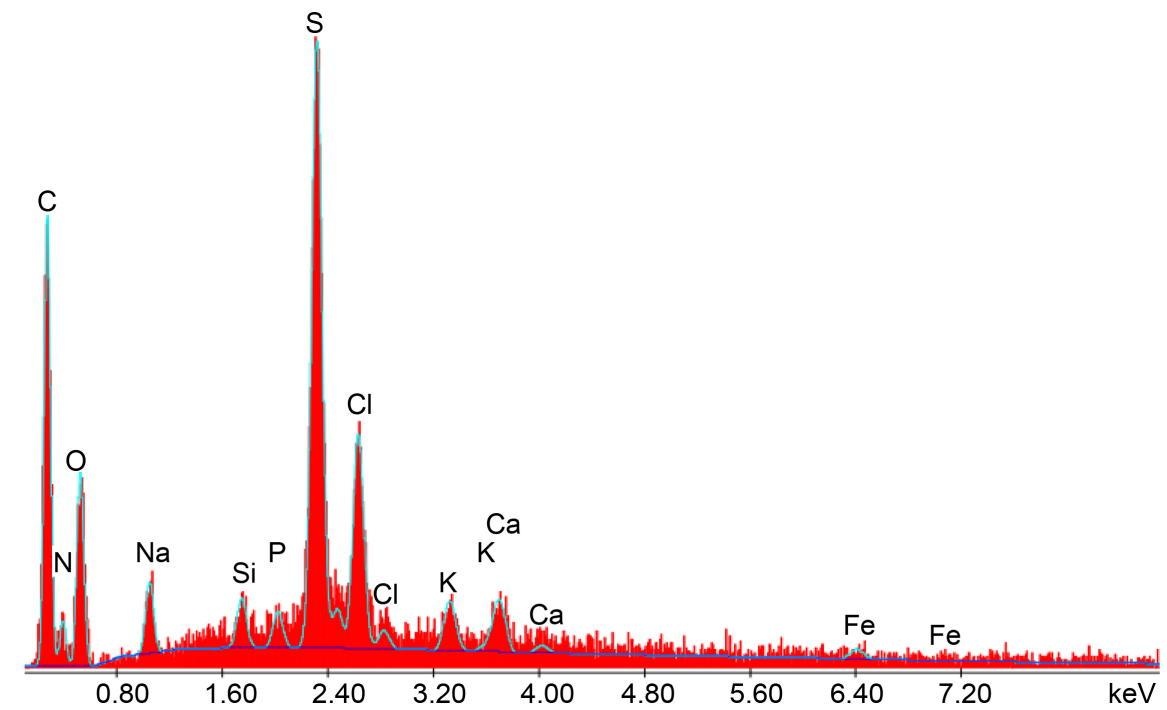

Figure 39. EDX microanalysis showing the presence of alumina, silica, Halite and Iron oxides in the mortar sample.

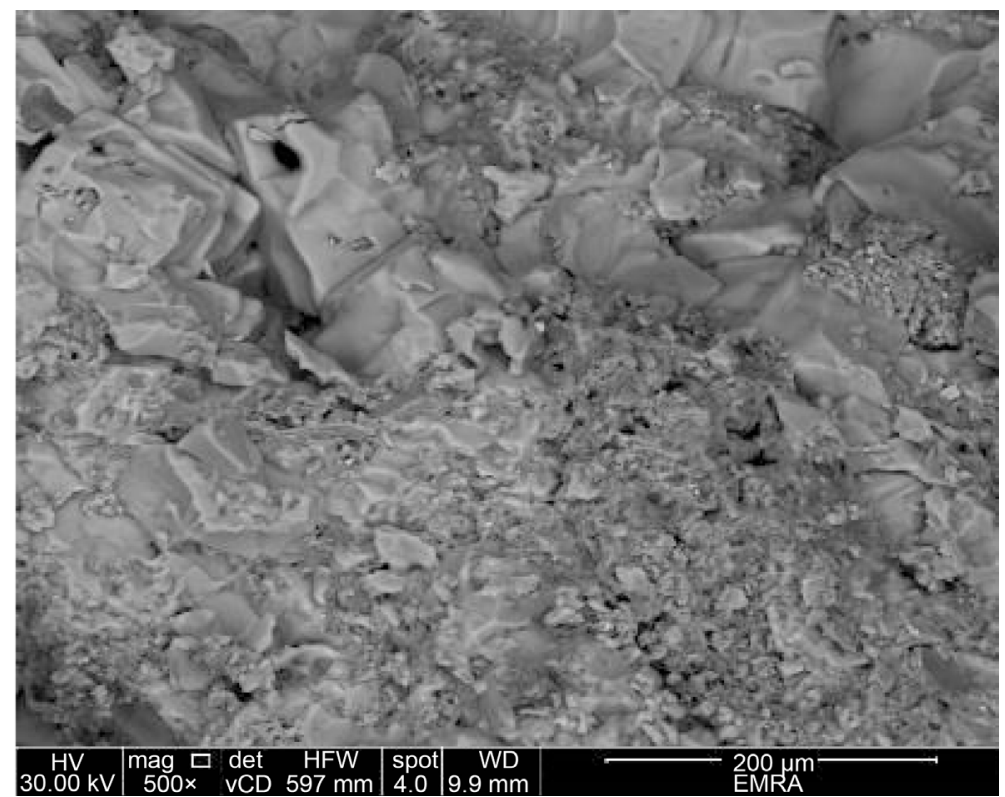

Figure 40. SEM image showing the presence of limestone and bricks aggregates and the contamination with the chloride salts.

related EDX analysis showed the presence of alumina and silica $\mathrm{Al}, \mathrm{Si}$ This indicates that it is a hydraulic lime mortars (Figure 37, Figure 39, Figure 41 and Figure 44).

The obtained results indicated the presence of Silica and Alumina as main elements in the mortar composition, which indicates that the structural mortar from Babylon of Egypt is a hydraulic lime mortars, in addition to the presence of calcite aggregates and iron oxides, and the presence of sodium chloride as result of salt contamination from soil and ground water. Figure 42 shows the presence of carbon and burned organic matters residues represented in phosphorus, 


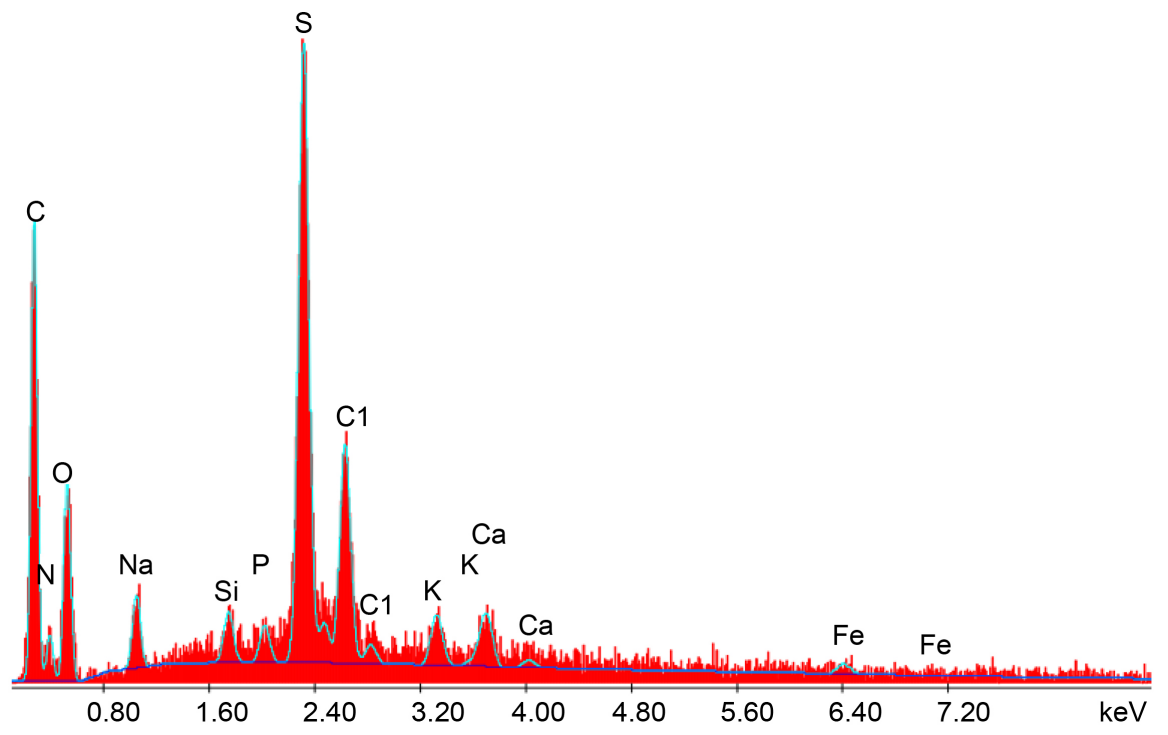

Figure 41. EDX microanalysis showing the presence of Carbon and residues of organic matter in the mortar samples.

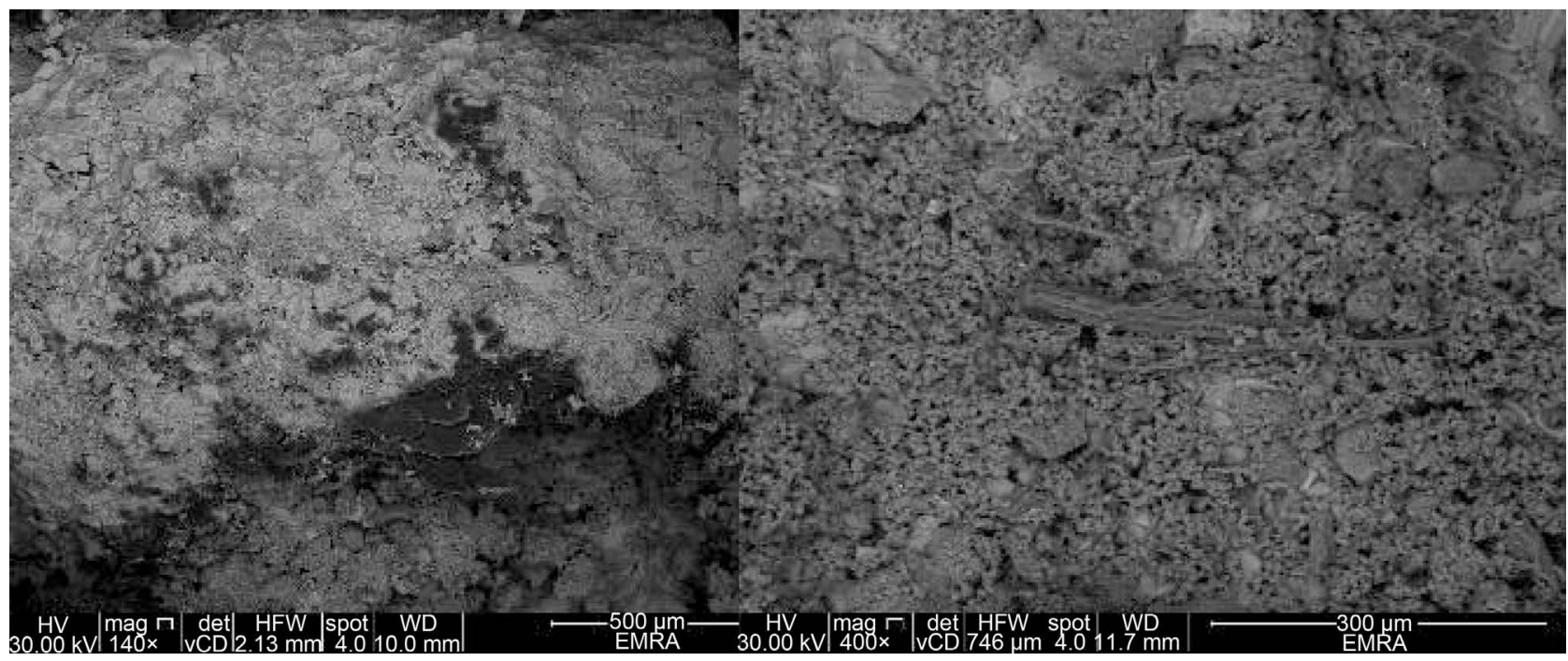

Figure 42. SEM image showing the disintegration of the structural mortars due to the ground water and salt weathering.

nitrogen and oxygen P, N, C (Figure 44). Shows the presence of alumina and silica inside the mortar composition, confirming that is a hydraulic mortar [20].

\section{Conclusions}

Red bricks and the hydraulic mortars were of the most important construction materials used in the Roman and Byzantine architecture including the subject of the present study "Babylon fortress" in the old Cairo.

Generally the studied fired brick is formed mainly of quartz and feldspar grains. These grains are embedded in a ferruginous dark brownish groundmass formed mainly of iron oxides (hematite) and burnt clays. The bricks have various colors and dimensions and formed mainly from local raw material (Nile sediments) 


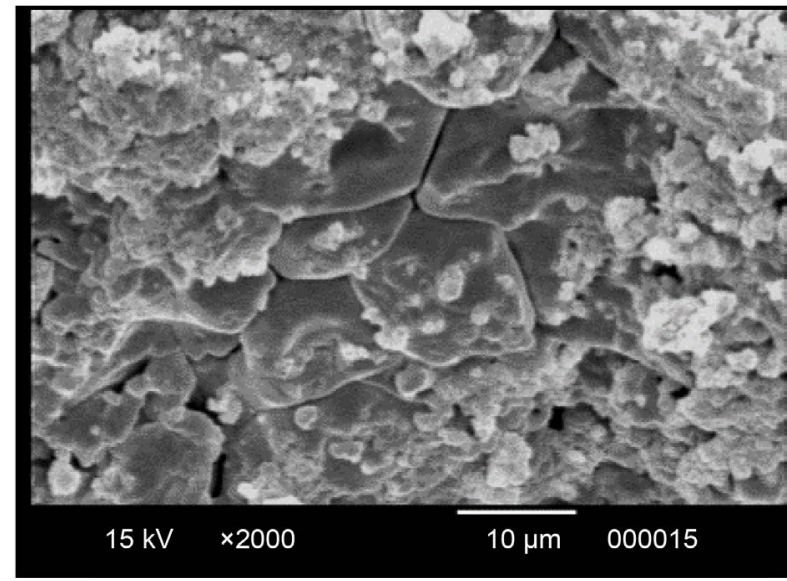

Figure 43. SEM image showing Quartz, Calcite and Halite Crystals in the mortar sample.

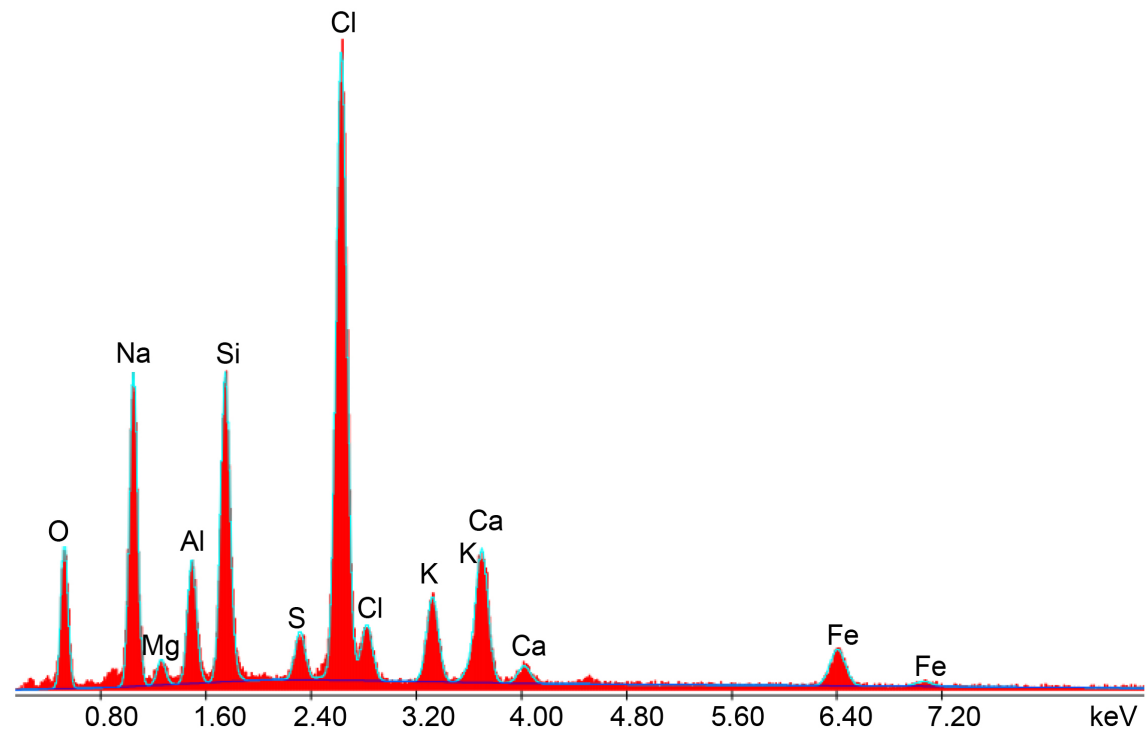

Figure 44. EDX microanalysis showing the presence of alumina and silica in the mortar that confirms that it is a hydraulic mortar.

together with some additives (rice hush and/or plant ash to improve their properties. They are of medium density, high porosity due to the weathering activities (subsurface water and salt weathering. They have wide range values of their physical and engineering characteristics (e.g. specific density, water absorption, porosity, ultrasonic velocity uniaxial compressive strength $\sigma_{\mathrm{c}}$, static modulus of elasticity, dynamic modulus of elasticity, and shear stress).

The joining structural mortars are ranging from medium to stiff, low compacted having hydraulic properties due to the use of natural furnace slag, homra (brick powder), brick fragments and aggregates that match with the pozzolanic properties and also rich in active silica and alumina. The examinations reveal the using of limestone fractions as coarse aggregates or fillers in the mortar.

Ground water and salt crystallization are major causes of deterioration of 
these porous building materials (brick and joining structural mortars), strongly related to the fluctuation of the surrounding environmental parameters.

This paper also explores the application of different methodologies to assess the potential damage caused by ground water and soluble salts to the studied roman bricks and hydraulic lime from the Babylon of Egypt, also to define the necessary characteristics of the intervention retrofitting new materials, which will be used in the ongoing preservation work of this fortress.

\section{References}

[1] Hemeda, S. (2013) Laser Induced breakdown Spectroscopy and other analytical techniques applied on construction materials at Kom El-Dikka, Alexandria, Egypt. Mediterranean Archaeology and Archaeometry, 13, 103-119.

[2] Adam, J.-P. (1994) Roman Buildings Materials and Techniques. Trans: Mathews, A. B. T. Batsford Ltd, London, 58-64.

[3] Stefanidou, M., Papayianni, I. and Pachta, V. (2015) Analysis and Characterization of Roman and Byzantine Fired Bricks from Greece. Materials and Structures, 48, 2251-2260. https://doi.org/10.1617/s11527-014-0306-7

[4] Binda, L., Saisi, A., De Benedictis, R. and Tringali, S., Exp. (2003) Study on the Damaged Pillars of the Noto Cathedral. Proceedings of the 8 th International Conference STREMAH, Halkidiki.

[5] Binda, L., Anzani, A., Pina-Henriques, J. and Tongini Folli, R. (2003) Sperimentazione su provini in muratura a tre paramenti. Workshop: Danneggiamento, conservazione e manutenzione di strutture murarie e lignee, DIS-Politecnico di Milano, Italy.

[6] Binda, L., Pina-Henriques, J., Anzani, A. and Fontana, A. (2006) A Contribution for the Understanding of Load Transfer Mechanisms in Multiple Leaf Masonry Walls: Testing and Modeling. Engineering Structure, 28, 1132-1148. https://doi.org/10.1016/j.engstruct.2005.12.004

[7] Hemeda, S. (2013) Geotechnical Characterization of Sakakini's Palace Stones and Other Construction Materials, Cairo-Egypt. Geomaterials, 3, 38-46.

https://doi.org/10.4236/gm.2013.31005

[8] Işıkdağ, B and Topçu, I.B. (2013) The Effect of Ground Granulated Blast-Furnace Slag on Properties of Horasan Mortar. Construction and Building Materials, 40, 448-454. https://doi.org/10.1016/j.conbuildmat.2012.11.016

[9] Gürdal, E., Altaş, G.K. and Özgünler, S.A. (2011) Investigation of Khorasan Mortar Properties Used in Early Age Byzantine Period Religious Structures. Annual of Restoration, Conservation, Archeology and Art History, 2, 63-72.

[10] Uğurlu, E and Böke, H. (2006) Properties of Horasan Plaster Used in the Baths of the Ottoman Time. Proceedings of the 3rd National Congress and Exhibition of Construction Materials, Istanbul, 585-596.

[11] Sabbioni, C., Bonazza, A. and Zappia, G. (2002) Damage on Hydraulic Mortars: The Venice Arsenal. Journal of Cultural Heritage, 3, 83-88. https://doi.org/10.1016/S1296-2074(02)01163-9

[12] Labiadh, M.R., Ouezdou, M.B., Hajjem, B.T. and Mensi, R. (2009) Characterization of Waterproof-Covering Mortars on Ottoman Monuments of "Ghar El Melh" (Tunisia). Construction and Building Materials, 23, 423-433.

https://doi.org/10.1016/j.conbuildmat.2007.11.007 
[13] Özkaya, Ö.A. and Böke, H. (2009) Properties of Roman bricks and mortars used in Serapis temple in the city of Pergamon, Turkey. Materials Characterization, 60, Issue 9.

[14] Papayianni, I. (2004) Design of Compatible Repair Materials for the Restoration of Monuments. International Journal for Restoration, 1, 623-639.

[15] Papayianni, I. (2006) The Longevity of Old Mortars. Applied Physics A: Materials Science\& Processing, 83, 685-688. https://doi.org/10.1007/s00339-006-3523-2

[16] Papayianni, I., Stefanidou, M. and Pachta, V. (2010) Grouts for Injection of Historical Masonries: Influence of the Binding System and Other Additions on the Properties of the Matrix. In: Proceedings of the 2nd Historic Mortars Conference and Rilem TCRHM “Repair Mortars for Historic Masonry”, RILEM Publications SARL, 1123-1134.

[17] Papayianni, I., Stefanidou, M. and Pachta, V. (2012) Experimental Study of Nano-Modified Lime Based Grouts. World Journal of Engineering, 9, 501-508. https://doi.org/10.1260/1708-5284.9.6.501

[18] Cook, D., Ledbetter, S., Ring, S. and Wentzel, F. (2000) Masonry Crack Damage: Its Origins, Diagnosis, Philosophy and a Basis for Repair. Proceedings of the Institution of Civil Engineers: Structures and Buildings, 140, 39-50.

https://doi.org/10.1680/stbu.2000.140.1.39

[19] Corti, C., Rampazzi, L., Bugini, R., et al. (2013) Thermal Analysis and Archaeological Chronology: The Ancient Mortars of the Site of Baradello (Como, Italy). Thermochimica Acta, 572, 71-84. https://doi.org/10.1016/j.tca.2013.08.015

[20] Stefanidou, M., Pachta, V. and Papayianni, I. (2013) Analysis of Historic Mortars from the Archaeological Site of Logos and Design of Repair Materials. In: Heritage Masonry: Materials and structures, Publisher WIT Press Editors, S. Syngellakis. 